\title{
Guidelines
}

Cerebrovascular Diseases
Cerebrovasc Dis 2013;35:93-112

DOI: $10.1159 / 000346087$
Received: October 9, 2012

Accepted: November 22, 2012

Published online: February 7, 2013

\section{European Stroke Organization Guidelines for the Management of Intracranial Aneurysms and Subarachnoid Haemorrhage}

\author{
Thorsten Steiner $^{\mathrm{a}}$ Seppo Juvela ${ }^{\mathrm{d}} \quad$ Andreas Unterberg $^{\mathrm{b}}$ Carla Jung ${ }^{\mathrm{b}}$ \\ Michael Forsting ${ }^{c}$ Gabriel Rinkel $^{\mathrm{e}}$
}

Departments of a Neurology and ${ }^{b}$ Neurosurgery, Heidelberg University, Heidelberg, and ${ }^{c}$ Department of Radiology, University of Essen, Essen, Germany; ' Department of Clinical Neurosciences, University of Helsinki, Helsinki, Finland; ${ }^{e}$ Department Neurology, Utrecht University, Utrecht, The Netherlands

\section{Key Words}

Subarachnoid haemorrhage · Intracranial aneurysm .

Perimesencephalic subarachnoid haemorrhage .

Management · Guidelines

\begin{abstract}
Background: Intracranial aneurysm with and without subarachnoid haemorrhage (SAH) is a relevant health problem: The overall incidence is about 9 per 100,000 with a wide range, in some countries up to 20 per 100,000 . Mortality rate with conservative treatment within the first months is $50-$ $60 \%$. About one third of patients left with an untreated aneurysm will die from recurrent bleeding within 6 months after recovering from the first bleeding. The prognosis is further influenced by vasospasm, hydrocephalus, delayed ischaemic deficit and other complications. The aim of these guidelines is to provide comprehensive recommendations on the management of SAH with and without aneurysm as well as on unruptured intracranial aneurysm. Methods: We performed an extensive literature search from 1960 to 2011 using Medline and Embase. Members of the writing group met in person and by teleconferences to discuss recommendations. Search results were graded according to the criteria of the
\end{abstract}

European Federation of Neurological Societies. Members of the Guidelines Committee of the European Stroke Organization reviewed the guidelines. Results: These guidelines provide evidence-based information on epidemiology, risk factors and prognosis of SAH and recommendations on diagnostic and therapeutic methods of both ruptured and unruptured intracranial aneurysms. Several risk factors of aneurysm growth and rupture have been identified. We provide recommendations on diagnostic work up, monitoring and general management (blood pressure, blood glucose, temperature, thromboprophylaxis, antiepileptic treatment, use of steroids). Specific therapeutic interventions consider timing of procedures, clipping and coiling. Complications such as hydrocephalus, vasospasm and delayed ischaemic deficit were covered. We also thought to add recommendations on SAH without aneurysm and on unruptured aneurysms. Conclusion: Ruptured intracranial aneurysm with a high rate of subsequent complications is a serious disease needing prompt treatment in centres having high quality of experience of treatment for these patients. These guidelines provide practical, evidence-based advice for the management of patients with intracranial aneurysm with or without rupture. Applying these measures can improve the prognosis of $\mathrm{SAH}$.

Copyright $\odot 2013$ S. Karger AG, Basel

Prof. Dr. Thorsten Steiner

Klinikum Frankfurt Höchst

Gotenstrasse 6-8

DE-65929 Frankfurt (Germany)

E-Mail Thorsten_steiner@med.uni-heidelberg.de
E-Mail karger@karger.com Accessible online at:

www.karger.com www.karger.com/ced 


\section{General Considerations}

\section{Introduction}

Subarachnoid haemorrhage (SAH) is a relevant health problem with an approximate incidence of 9 per 100,000 and a mortality rate of about $60 \%$ within 6 months. The prognosis is influenced by multiple nonmodifiable factors and by factors that can be influenced by therapeutic interventions and management procedures. International guidelines are only available in the United States [1]. However, those guidelines mainly deal with SAH from ruptured aneurysm and there might be some differences in the conception of technical and management aspects and in terms of epidemiology. Therefore, it is necessary to publish guidelines on the management of SAH and unruptured aneurysms from a European standpoint.

The writing group consists of experts in neurology, neurosurgery, neuroradiology and neurointensive care medicine. We performed a literature search including all available literature using Medline and Embase. Literature was evaluated and assessed using the predefined criteria of the European Federation of Neurological Societies [2]. Level of evidence is reported in classes from I to IV. Recommendations are rated by levels A-C and GCP (good clinical practice).

\section{Definitions - Terminology}

\section{Statement on Definition}

- We differentiate 'ruptured intracranial aneurysm' (RIA) from 'unruptured intracranial aneurysm' (UIA); the latter can either be 'asymptomatic' or 'symptomatic'

- A symptomatic UIA usually causes brain nerve palsy or rarely can cause arterial embolism

- Asymptomatic UIAs are usually found incidentally ('incidental aneurysm') because of symptoms unrelated to aneurysm (long-term headache, dizziness, etc.) or can be discovered after SAH as an 'additional aneurysm', which is not the bleeding source

\section{Clinical Appearance and Grading}

In aneurysmal SAH three variables are most closely related to outcome: the neurological condition of the patient on admission, age, and the amount of extravasated blood seen on CT scans. The neurological condition, particularly the level of consciousness, is the most important determinant for outcome after SAH. There- fore, since the neurological condition can change during the clinical course after $\mathrm{SAH}$, it is important to have a reliable (i.e. high inter- and intra-observer agreement) and valid (i.e. good relation with outcome) grading system for unequivocal and understandable documentation. Several grading systems, in most cases consisting of approximately 5 categories of severity, have been developed for the initial assessment of SAH patients. A still widely used scale is that of Hunt and Hess [3]: besides the level of consciousness (graded into drowsiness, stupor and deep coma), headache (minimal, moderate and severe), neck stiffness (slight nuchal rigidity vs. nuchal rigidity) and focal neurological deficits (mild, moderate and severe hemiparesis) constitute this scale. Due to the unclear definition of the neurological status described above, this scale is neither reliable nor valid [4]. As grading scales based on the Glasgow Coma Scale (GCS) have the advantage of a reasonable inter-observer agreement, a committee of the World Federation of Neurological Surgeons (WFNS) proposed a grading scale of again five levels, essentially based on the GCS, with focal deficits making up one extra level for patients with a GCS of 14 or 13 [5]. The cut-off points in the WFNS scale are based on consensus, not on formal analysis. Another scale based on the GCS, and assessed only retrospectively, performed better than the Hunt and Hess scale and the WFNS scale [6]. For one grading scale based solely on the GCS, the Prognosis on Admission of Aneurysmal Subarachnoid Haemorrhage (PAASH) grading scale, the cut-off points between the categories were selected by calculating at which point 2 consecutive categories corresponded to a statistically significant different outcome at 6 months [7]. This PAASH scale has a good internal and external validity in regard to clinical outcome [8]. In a study comparing prognostic accuracy, both scales, WFNS and PAASH, had a good prognostic value for patient outcome. However, the PAASH scale showed a more gradual increase in the proportionate distribution of patients with poor outcome per each increasing PAASH grade than the WFNS scale and seems, therefore, slightly preferable to the WFNS scale (table 1) [8].

Recommendation

- It is recommended that the initial assessment of SAH patients, and therefore the grading of the clinical condition, is done by means of a scale based on the GCS

- The PAASH scale performs slightly better than the WFNS scale, which has been used more often (class III, level C)
Steiner/Juvela/Unterberg/Jung/Forsting/ Rinkel 
Table 1. Two SAH grading scales with criteria per grade and relation with outcome

\begin{tabular}{lllll}
\hline Scale & Grade & Criteria & $\begin{array}{l}\text { Proportion of } \\
\text { patients with } \\
\text { poor outcome }\end{array}$ & $\begin{array}{l}\text { OR } \\
\text { for poor } \\
\text { outcome }\end{array}$ \\
\hline WFNS & I & GCS 15 & $14.8 \%$ & $\begin{array}{l}\text { reference } \\
\end{array}$ \\
& II & GCS 13-14 & & 2.3 \\
& no focal deficits & $29.4 \%$ & \\
& III & GCS 13-14 & & 6.1 \\
& IV & focal deficits & $52.6 \%$ & 7.7 \\
& V V & GCS 3-12 & $58.3 \%$ & 69 \\
PAASH & I & GCS 15 & $92.7 \%$ & reference \\
& II & GCS 11-14 & $41.8 \%$ & 3.9 \\
& III & GCS 8-10 & $74.4 \%$ & 16 \\
& IV & GCS 4-7 & $84.7 \%$ & 30 \\
& V & GCS 3 & $93.9 \%$ & 84 \\
\hline
\end{tabular}

Poor outcome defined as Glasgow outcome scale 1-3 or modified Rankin score 4-6. WFNS = World Federation of Neurological Surgeons Grading Scale for Subarachnoid Haemorrhage [5]. PAASH = Prognosis on Admission of Aneurysmal Subarachnoid Haemorrhage grading scale [7]. GCS = Glasgow Coma Score [157]. Data in this table are adapted from van Heuven et al. [8].

\section{Aneurysmal SAH - Ruptured Aneurysm (RIA)}

\section{Epidemiology}

\section{Incidence}

The incidence of SAH varies widely throughout the world. An estimate of 9.1 (95\% confidence interval, CI, $8.8-9.5)$ per 100,000 per year is generally accepted as the overall incidence of SAH worldwide, with the exclusion of the regionally high incidences in Finland and Japan [9]. In Finland and Japan incidences of SAH of 15-17 per 100,000 per year during the CT era and of 22.7 per 100,000 per year (95\% CI, 21.9-23.5) were reported, respectively [9-12]. SAH incidence increases linearly with patient age. The median age of onset at the first SAH is $50-60$ years. Furthermore, the incidence of SAH is approximately 1.6 times higher in women than in men, but the predominance of women is not apparent until the fifth decade [9-11]. In general, there is a tendency of reduction in incidence during later decades $[9,10,12]$.

Intracranial aneurysms in the general population as well as in selected populations have been studied in various retrospective and prospective autopsy and angiography studies [11]. Among adults, the prevalence appears to be $2-5 \%$. Reported frequencies of unruptured aneurysms in angiographic and prospective autopsy series is approximately $3-4 \%$ [11]. Those with a family history of aneurysms have a higher prevalence of $9.5 \%$. More than $90 \%$ of aneurysms are less than $10 \mathrm{~mm}$ in diameter and $90 \%$ exist in anterior cerebral circulation.

\section{Statement on Incidence}

- The overall incidence of SAH is 9.1 per 100,000 person-years in most regions, and is higher in Finland and Japan; in the European community that means around $36,000 \mathrm{SAH}$ cases per year

\section{Outcome/Prognosis}

Data on the natural history of aneurysmal SAH is very poor. The most reliable knowledge of the natural history of ruptured saccular intracranial aneurysms has been obtained from a study reported by Pakarinen [13] with an unselected population and few surgical withdrawals [13, 14]. Cumulative case fatality rates over time after $\mathrm{SAH}$ are as follows: day 1: 25-30\%; week 1: 40-45\%; first month: 50-60\%; sixth month: 55-60\%; year 1: $65 \%$ and year 5 after SAH: $65-70 \%$. Approximately $12 \%$ of patients die before reaching medical attention [15].

If those patients who die before medical attention are included, $43 \%$ of all SAH patients die without recovering from the initial bleeding [13]. Of those, $74 \%$ die within the first $24 \mathrm{~h}, 7 \%$ within $2-3$ days, $12 \%$ within $4-7$ days, $5 \%$ within week $2,1 \%$ within week 3 , and $1 \%$ later than 3 weeks after the initial SAH [13].

If a ruptured aneurysm is left untreated, about one third of the patients who recover from the initial haemorrhage die because of recurrent bleeding within 6 months after $\mathrm{SAH}[13,16]$. The cumulative risk of rebleeding by 6 months after $\mathrm{SAH}$ is $50 \%$. Thereafter, the annual risk of rebleeding decreases to $3 \%$ during the next 10 years. Two thirds of these late, recurrent bleedings cause death [17-19].

Despite improvements in surgical and medical treatment, rupture of an aneurysm is still associated with high rates of case fatality (roughly one third) and of severe disability (one sixth) [14, 20]. Between 1973 and 2002 case fatality rate decreased by approximately $17 \%$ [21], and the possibility to recover an independent state has increased by $1.5 \%$ per year [14]. However, data on recovery are based only on a few studies with a small number of patients.

Case fatality and functional outcome after SAH are determined by the severity of the initial bleeding $[14,22$, 23]. Another very important parameter is age, with a tripled case fatality in octogenarians compared with young adults [22-26]. Other determinants are aneurysm site [24] and size [23, 24], history of hypertension [22-24], high systolic blood pressure [23] and heavy alcohol con- 
sumption [22]. All these factors have been reported independently of the severity of SAH to predict outcome. In addition, in a large meta-analysis cigarette smoking has been reported to increase the risk for delayed cerebral ischaemia (DCI) [27]. The role of biomarkers for evaluation has not been studied in large cohorts. Small studies suggest that catecholamine levels in cerebrospinal fluid (CSF) are elevated in patients who experience early mortality or disability [28]. Serum S100 has been associated with poor outcome after SAH [29].

After aneurysm rupture, the possibility of poor outcome rises because of different factors: (1) disease-associated events (e.g. rebleeding, DCI, hydrocephalus), (2) treatment-associated factors [surgical (clipping) or endovascular (coiling) complications] and (3) complications associated with prolonged bed rest [14, 22-24, 30]. Aneurysm rupture itself can cause stress hyperglycaemia, cardiopulmonary complications and increased blood coagulability, which, independent of severity of bleeding or of metabolic syndrome, may elevate the risk of poor outcome [25, 30-32]. Outcome after SAH is thus probably determined by multiple independent factors.

There are not many data on health-related quality of life (HRQoL) after SAH. HRQoL may be remarkably reduced in patients with SAH compared to the normal population. Female gender, severe SAH, functional disability, depression, lower level of education and the lack of a stable partnership were found to be independent predictors of HRQoL [33].

\section{Risk Factors}

Risk Factors can be divided into risk factors for SAH, aneurysm formation and aneurysm growth.

Independent modifiable risk factors for SAH seem to be only cigarette smoking, excessive alcohol consumption and hypertension (class III evidence) [34-36].

\section{Cigarette Smoking}

Cigarette smoking is an independent and the most important risk factor for $\mathrm{SAH}$, which has already been proved in several cohort (relative risk, RR of current smoking, 2.2) and case-control studies (odds ratio, OR, 3.1) all over the world [34-38]. In North America and Europe, the prevalence of smoking in SAH patients ranges from 45 to $75 \%$ whereas in the general adult population it is $20-35 \%$. Of SAH cases, $40 \%$ can be attributed to cigarette smoking [35-39].

After diagnosis of an unruptured aneurysm, the size of aneurysm [40-42], and possibly location [41], age inversely [42] and cigarette smoking [42] are independent predictors for subsequent aneurysm rupture. The adjusted RR of cigarette smoking for aneurysm rupture, tested as a time-dependent covariate, was 3.0 (95\% CI, 1.2-7.7) if the patient continued smoking during followup [42].

In a prospective follow-up study, cigarette smoking and female gender were only significant independent factors affecting both aneurysm formation and growth [43]. Women in particular were at higher risk for aneurysm formation than men, and cigarette smoking hastened aneurysm growth rate. These findings are important since aneurysms grow before the rupture. The faster the growth, the more likelihood there is of rupture [43].

\section{Alcohol Use}

The role of alcohol as a risk factor for SAH has not been as well established as smoking. Several cohort (RR $>150 \mathrm{~g} /$ week, 2.1) and case-control (OR >150 g/week, 1.5) studies have shown that excessive alcohol consumption increases the risk for SAH in both men and women, independently of cigarette smoking, age, and history of hypertension [34-38]. In the study from Ruigrok et al. [39], drinking more than $300 \mathrm{~g} /$ week of alcohol attributed to $20 \%$ of instances of SAH in the population, and drinking 100-299 $\mathrm{g} /$ week accounted for $11 \%$ of cases of SAH $[36,39]$.

\section{Hypertension}

History of hypertension as a risk factor for SAH (RR, 2.5; OR, 2.6) seems to be less crucial than for other stroke subtypes [34-38]. The prevalence of hypertension among SAH patients (20-45\%) is somewhat higher than in the general population; after adjustment for age, gender, cigarette smoking and alcohol consumption, history of hypertension has not been shown to significantly increase the risk for $\mathrm{SAH}$, as demonstrated in 2 case-control studies $[36,38]$. However, combining all cohort and case-control studies, hypertension still was an important risk factor [34].

In a long-term cohort study, patients with hypertension did not have de novo aneurysms or aneurysm growth more often than non-hypertensive patients, nor did blood pressure values during follow-up correlate with aneurysm formation or growth [43]. However, patients who had used antihypertensive medication may have decreased risk for aneurysm formation [43]. On the other hand, in another long-term follow-up study hypertension at the time of the initial SAH was a risk factor for de novo aneurysm formation [44].
Steiner/Juvela/Unterberg/Jung/Forsting/ Rinkel 


\section{Statement}

- Hypertension can be considered to be an important risk factor for SAH and possibly for aneurysm formation and fatal aneurysm rupture

- Cigarette smoking is the most important modifiable risk factor for aneurysm formation, growth and rupture, and should be discouraged

- Alcohol abuse and particularly sudden intake of high quantities is a risk factor for aneurysm rupture and should be desisted

(class III, level C)

\section{Family History}

Recently, family history of intracranial aneurysms has been suggested to be evidence for genetic causality of cerebral aneurysms [35, 45-47]. However, cigarette smoking and other health-related habits should be analysed as a confounding factor for this association since correlation of these habits between family members is higher than in the general population $[45,48]$. Smoking and alcohol intake habits may even to some degree be influenced by genetic factors [48]. Part of the familial preponderance may also be attributed to familial occurrence of hypertension $[49,50]$.

Less than $10 \%$ of SAH can be attributed to first-degree relatives only $[35,39,45]$, and $5-8 \%$ to first or seconddegree relatives $[35,45]$. Also, many studies show that around $10 \%$ of patients with SAH have a family history. The chance of finding an aneurysm at screening is around $10 \%$ if 2 or more first-degree relatives are affected [51-57]. A family history of polycystic kidney disease seems to increase the risk of SAH [11].

\section{Recommendation}

- Screening should in general not be advised in the case of only 1 affected first-degree relative

- If 2 or more first-degree relatives are affected, the lifetime risk of SAH in the other relatives is considerable, and screening should be considered (class III, level C)

\section{Other Risk Factors}

Besides the above-mentioned risk factors many other factors have been implicated in the pathogenesis of saccular aneurysms and SAH. Of these, non-white ethnicity has been associated with increased risk for $\mathrm{SAH}$, while hormone replacement therapy among women, hypercholesterolemia, and diabetes mellitus may reduce this risk [34]. According to a recent systematic review, the use of oral contraceptives does not seem to affect SAH risk, and the significance of low body mass index or rigorous exercise seems inconsistent [34]. Of these, low serum total cholesterol and triglyceride levels may be independent of cigarette smoking and hypertension risk factors for SAH [58].

The annual rate of new (de novo) aneurysm formation was $0.6-0.9 \%$ in patients with a treated ruptured aneurysm $[43,59,60]$. These angiographic follow-up studies were done for all survivors and not only for those with a later new SAH, as this kind of patient selection erroneously would have increased this formation rate. Women and cigarette smokers had independently increased risk (OR, 4-5) for de novo aneurysm formation [43]. De novo aneurysms developed during a mean follow-up time of 19 years, a follow-up period not differing significantly from that of those without de novo aneurysms. In cases where a de novo aneurysm caused SAH, the follow-up time was somewhat shorter ( $14.7 \pm 8.1$ years; range, $3.4-$ 28.4 years) [43].

MR angiography (MRA) follow-up of 610 patients with a mean follow-up of 9 years after SAH revealed a cumulative $16 \%$ chance of finding a new aneurysm [44]. In this study, risk factors for aneurysm formation and growth were the presence of multiple aneurysms at time of SAH (hazard ratio, HR, 3.2; 95\% CI, 1.2-8.6), current smoking (HR, 3.8; 95\% CI, 1.5-9.4) and hypertension (HR, 2.3; 95\% CI, 1.1-4.9).

Of 752 SAH patients with 6,016 follow-up years (mean follow-up 8.0 years), 18 had a recurrence of SAH. In the first 10 years after the initial SAH, the cumulative incidence of recurrent SAH was 3.2\% (95\% CI, 1.5-4.9\%) and the incidence rate was 286 of 100,000 patient-years ( $95 \%$ CI, 160-472 per 100,000). Risk factors were smoking (HR, 6.5; 95\% CI, 1.7-24.0), age (HR, 0.5 per 10 years; $95 \%$ $\mathrm{CI}, 0.3-0.8)$ and multiple aneurysms at the time of the initial SAH (HR, 5.5; 95\% CI, 2.2-14.1). Thus, after SAH, the incidence of a recurrence within the first 10 years is $22(12-38)$ times higher than expected in populations with comparable age and sex. Whether this increased risk justifies screening for recurrent aneurysms in patients with a history of SAH requires further study [44, $60]$.

\section{Statement on Risk Factor}

- Risk factors for SAH can be divided into risk factors for aneurysm formation, aneurysm growth and rupture

- The most important modifiable risk factors for SAH: cigarette smoking, hypertension and excessive alcohol intake, and nonmodifiable risk factors: sex, age, size of aneurysm and family history

- Risk factors for de novo formation of aneurysms: female sex, current cigarette smoking, hypertension, age (at diagnosis) and family history

- Risk factors for aneurysm growth: current cigarette smoking
Guidelines for Management of

Intracranial Aneurysms and $\mathrm{SAH}$
Cerebrovasc Dis 2013;35:93-112 DOI: $10.1159 / 000346087$ 


\section{Diagnosis}

Subarachnoid blood is almost always detectable on CT scans on the first day of SAH with its typical distribution in the subarachnoid space/basal cisterns. Therefore, if SAH is clinically suspected a cranial CT should be performed to confirm the diagnosis. Modern CT technology provides a sensitive method to detect subarachnoid blood in the early phase after SAH. However, sensitivity of CT decreases with resorption and redistribution of subarachnoid blood over the time course after the initial SAH: 5 days after the initial bleeding SAH is detectable in about $85 \%$ of cases and after 2 weeks in under $30 \%$ of SAH cases. MRI with Flair technology seems comparable with CT in the acute phase of SAH [61]. In the weeks following SAH, MRI is clearly superior to CT [62] and reveals a reliable tool in the follow-up of endovasculartreated aneurysms. After surgical treatment (clipping) of aneurysms MRI is of reduced value due to metal artefacts. In the case of anamnestically or clinically suspected $\mathrm{SAH}$, despite negative/inconspicuous CT and/or MRI scans, a lumbar puncture has to be performed. Waterclear, normal CSF excludes SAH within the last 2-3 weeks. In the case of bloody CSF a traumatic tap must be kept in mind. More assuring than bloody CSF but not specific is the detection of xanthochromia caused by degradation of blood. As blood degradation takes some hours, lumbar puncture is recommended 6-12 $\mathrm{h}$ after the initial SAH.

Cerebral panangiography continues to be the gold standard for detection, demonstration and localization of ruptured aneurysms. Complication rate of this invasive diagnostic procedure is below $0.5 \%$ in experienced centres [63]. Further less invasive methods are MRA and CT angiography (CTA) $[62,63]$. MRA is a secure procedure, which was reported to be less sensitive than digital subtraction angiography (DSA, conventional angiography) and less feasible in agitated patients or those who require monitoring during the acute phase after SAH. CTA is less time consuming than MRA. Sensitivity and specificity of CTA detecting cerebral aneurysms are described to be $0.77-0.97$ and $0.87-1.00$, respectively. However, sensitivity decreases with aneurysm size: for small aneurysms $(<3 \mathrm{~mm})$ CTA sensitivity ranges around $0.4-0.9$. A similar loss of sensitivity is reported and observed in MRA $[64,65]$. In the context of further prospective improvement of CTA and MRA technology a decrease in DSA is anticipated. Recently, Agid et al. [66] showed that CTA in patients with a specific CT pattern of subarachnoid blood distribution is as good as DSA.
Recommendation for Diagnosis

- CT/CTA and MRI with multiple sequences are equally suitable for the diagnosis of SAH within $24 \mathrm{~h}$ (class II, level B)

- CT/CTA and multisequential MRI/MRA may confirm the underlying cause

- Lumbar puncture must be performed in a case of clinically suspected SAH if CT or MRI does not confirm the diagnosis (class II, level B); however, within the first 6-12 h the differentiation between genuine subarachnoidal blood and traumatic admixture of blood may be difficult

- DSA of all cerebral arteries should be performed if a bleeding source was not found on CTA and the patient has a typical basal SAH pattern on CT (class II, level B)

- If no aneurysm was found, CTA or DSA should be repeated as described below: SAH without aneurysm (class III, level C)

\section{Treatment}

\section{General Medical Management}

Monitoring and Physical Management

Recommendations for monitoring and general management are summarized in table 2. Patients should be under continuous observation in an intensive care unit, or in an intermediate care facility of a stroke or neurovascular unit [67]. Staff in this unit should have ample experience in assessing swallowing function to prevent pneumonia, a frequent complication after SAH and independent risk factor for poor outcome [68]. ECG, level of consciousness (GCS), focal deficits, temperature and pupils should be monitored frequently for at least the first 7 days after $\mathrm{SAH}$, or longer as required depending on the patient's clinical condition. A urinary catheter is advised in all patients as well as a calculated fluid balance every 6 $\mathrm{h}$ during the initial week. In the intensive care unit, blood pressure is monitored continuously via an arterial line. Patients in a good clinical condition in whom the aneurysm has been secured may be transferred to a regular care bed in the stroke unit.

Headache can sometimes be managed with just mild analgesics such as paracetamol (acetaminophen); salicylates are best avoided because their antihaemostatic effect is unwanted in patients who may have to undergo external ventricular drainage and interferes with possibly pending neurosurgical interventions. In practice, the pain is usually so severe that codeine and even a synthetic opiate might be needed.

\section{Statement on Physical Management}

- To avoid situations that increase intracranial pressure, the patient should be kept in bed and the application of antiemetic drugs, laxatives and analgetics should be considered before occlusion of the aneurysm (GCP)
Steiner/Juvela/Unterberg/Jung/Forsting/ Rinkel 


\section{Glucose}

Hyperglycaemia develops in one third of SAH patients. Hyperglycaemia is associated with poor clinical condition on admission, and is independently associated with poor outcome $[25,30,31,69]$. Whether correction of hyperglycaemia results in improved outcome remains unclear. In a small trial comparing intensive versus conventional insulin therapy, intensive therapy reduced infection rate during the initial 14 days after admission. However, the trial was too small to detect differences in clinical outcome [70] (class III, level C).

Recommendation for Blood Glucose Management

- Hyperglycemia over $10 \mathrm{mmol} / \mathrm{l}$ should be treated (GCP)

\section{Temperature}

Despite treatment with paracetamol to relieve pain, fever develops in more than half of all SAH patients [71], predominantly in those with poor clinical condition on admission and in those with intraventricular extension of the haemorrhage [71]. Furthermore, fever is an independent risk factor for poor outcome [69]. In around $20 \%$ of patients no infection is found, and fever is attributed to inflammatory responses to extravasated blood in the subarachnoid space. There are neither controlled studies on the effect of cooling in SAH patients nor studies that have shown that treatment of fever does improve outcome. A randomized trial of mild hypothermia $\left(33^{\circ} \mathrm{C}\right)$ during aneurysm surgery after $\mathrm{SAH}$ showed no benefit [72].

\section{Recommendation for Temperature Management}

- Increased temperature should be treated medically and physically (GCP)

\section{Arterial Blood Pressure}

The treatment of high blood pressure after SAH remains controversial because of lack of evidence from randomized trials. Data from observational studies suggest that aggressive treatment of blood pressure may decrease the risk of rebleeding but at the cost of an increased risk of secondary ischaemia [73]. It seems reasonable, but without good evidence, to stop any antihypertensive medication that the patients were using and not to treat hypertension unless the blood pressure is extreme. It is not possible to give limits for 'extreme' blood pressures, because 'extreme' differs in different patients according to their age, previous blood pressure, cardiac history and other factors. If the aneurysm is not yet secured it seems prudent to treat blood

Guidelines for Management of

Intracranial Aneurysms and $\mathrm{SAH}$
Table 2. Recommendations for monitoring and general management of patients with aneurysmal SAH

Monitoring

- Intensive continuous observation at least until occlusion of the aneurysm

- Continuous ECG monitoring

- Start with GCS, focal deficits, blood pressure and temperature at least every hour

Blood pressure

- Stop antihypertensive medication that the patient was using

- Do not treat hypertension unless it is extreme; limits for extreme blood pressures should be set on an individual basis, taking into account age of the patient, pre-SAH blood pressures and cardiac history; systolic blood pressure should be kept below $180 \mathrm{~mm} \mathrm{Hg}$, only until coiling or clipping of ruptured aneurysm, to reduce risk for rebleeding

Fluids and electrolytes

- Intravenous line mandatory

- Insert an indwelling urinary catheter

- Start with 3 litre/day (isotonic saline, 0.9\%), and adjust infusion for oral intake

- Aim for normovolaemia also in case of hyponatraemia and compensate for fever

- Monitor electrolytes, glucose and white blood cell count at least every other day

Pain

- Start with paracetamol (acetaminophen) 500 mg every 3-4 h; avoid aspirin before aneurysm occlusion

- For severe pain, use codeine, tramadol (suppository or i.v.) or, as a last resort, piritramide (i.m. or i.v.)

Prevention of deep venous thrombosis and pulmonary embolism

- Compression stockings and intermittent compression by pneumatic devices in high-risk patients

pressure if the systolic pressure exceeds $180 \mathrm{~mm} \mathrm{Hg}$, for example by means of esmolol or labetolol [74]; it seems reasonable to aim for a modest (e.g. 25\%) decrease in mean arterial pressure.

Recommendation for Blood Pressure Management

- Until coiling or clipping, systolic blood pressure should be kept below $180 \mathrm{~mm} \mathrm{Hg}$; this may be already achieved by applying analgetics and nimodipine (GCP)

- If systolic pressure remains high despite these treatments further lowering of blood pressure should be considered (class IV, level C)

- If blood pressure is lowered the mean arterial pressure should be kept at least above $90 \mathrm{~mm} \mathrm{Hg}$ (GCP)

Thromboprophylaxis

In a placebo-controlled trial of enoxaparin (a low-molecular-weight heparin) administered subcutaneously 40 
mg once a day after surgical aneurysm occlusion, intracranial bleeding complications occurred somewhat more often in the enoxaparin group while there was no overall influence on outcome or appearance of post-SAH cerebral infarction $[75,76]$. Enoxaparin also increased the incidence of postoperative intracranial haemorrhage when initiated pre-operatively for deep venous thrombosis prophylaxis in patients with brain tumours [77].

Because of this increased risk of intracranial bleeding from thromboprophylaxis by means of low-molecularweight heparins, the use of stockings or pneumatic devices seems more appropriate in SAH patients. A study with non-randomized controls suggested that deep vein thrombosis can be successfully prevented by the use of pneumatic devices [78]. A Cochrane review on the use of graduated compression stockings or intermittent pneumatic compression in patients with stroke did not find support for the use of either method [79]. In a randomized trial in patients with intracerebral haemorrhage (ICH), the combination of stockings and intermittent pneumatic compression resulted in a smaller risk of deep venous thrombosis than prevention by stockings alone [80]. This combination may be the preferred strategy because there is no reason to suppose that this effect would be any different in patients with SAH, but it needs further study.

\section{Recommendation for Thromboprophylaxis}

- Patients with SAH may be given thromboprophylaxis with pneumatic devices and/or compression stockings before occlusion of the aneurysm (class II, level B)

- In case deep vein thrombosis prevention is indicated, lowmolecular-weight heparin should be applied not earlier than $12 \mathrm{~h}$ after surgical occlusion of the aneurysm and immediately after coiling (class II, level B)

\section{Antiepileptic Treatment}

Seizures at onset occur in around $7 \%$ of patients, but their impact on prognosis is uncertain [81]. Another 10\% develop seizures in the first few weeks [82], and convulsive status epilepticus occurs in $0.2 \%$ [83]. In patients who are comatose, non-convulsive status epilepticus has been detected in $8 \%$ of patients [84], but the proportion in this study might be an overestimation due to selection of EEG by indication. Whether continuous EEG monitoring should be performed in all SAH patients or in the subset that is comatose is an unresolved issue. In 1 retrospective study continuous EEG monitoring had additional prognostic information for poor outcome [85], but there are no data that outcome is improved by continuous EEG monitoring. Of all 8 instances of non-convulsive status epilepticus detected by continuous EEG monitoring in 101 co- matose SAH patients, only 1 patient temporarily improved after antiepileptic treatment, and all 8 patients eventually died [84]. Since prolonged EEG recording is expensive, labour intensive, subject to misinterpretation [86], and lacks proof of effectiveness, there are no grounds to use it as part of the routine monitoring strategy in patients with SAH.

Predictive factors for epileptic seizures have not been identified. Intracranial surgery increases the risk [87], but a randomized trial of antiepileptic drugs after supratentorial craniotomy for benign lesions (not only aneurysms) in 276 patients failed to show benefit in terms of seizure rate or case fatality, although the CIs were wide [88]. Also, an observational study performed on 3,552 patients participating in 4 prospective, randomized, double-blind, placebo-controlled trials suggested that outcome was worse in the $65 \%$ of patients receiving prophylactic antiepileptic drugs than in the other $35 \%$ of patients who did not receive prophylactic antiepileptic medication [89]. Given the lack of evidence in favour of prophylactic treatment with antiepileptic drugs and the possible disadvantage of serious adverse drug reactions, the current advice should be not to start antiepileptic drugs as prophylactic treatment.

Recommendation for Seizure Management

- Antiepileptic treatment should be administered in patients with clinically apparent seizures (GCP)

- There is no evidence that supports the prophylactic use of antiepileptic drugs (class IV, level C)

\section{Steroids}

A Cochrane review last updated in 2005 found 1 placebo-controlled trial on hydrocortisone in patients with SAH [90]. There was no difference in clinical outcome between patients with secondary ischaemia treated with hydrocortisone and those treated with placebo, but the risk of hyperglycaemia almost doubled [90]. A randomized trial published after the Cochrane review showed that in patients treated with hydrocortisone, serum sodium level and plasma osmolarity were controlled better than in controls, but clinical outcome was not better [91]. Based on these studies, routine hydrocortisone for patients with SAH is not warranted.

Statement on the Use of Steroids

- There is no proof that steroids are effective in patients with SAH (class IV, level C)

\section{Specific Prevention of Rebleeding}

General Considerations - Timing

Up to $15 \%$ of patients rebleed during the first few hours after the initial haemorrhage [92], that is, during trans- 
portation or before the treatment team is able to occlude the aneurysm. Patients surviving the first day after the initial SAH have a cumulative risk of $35-40 \%$ to suffer rebleeding of the aneurysm with a mortality rate of about $40 \%$. After 4 weeks the risk of rebleeding decreases to about 3\%/year [93].

The primary goal of the treatment of aneurysmal SAH is the occlusion of the ruptured aneurysm, i.e. to close the bleeding source preventing a rebleeding. For this, two major treatment options are available: neurosurgical clipping and endovascular coiling. A meta-analysis of 11 out of 268 studies with a total of 1,814 patients revealed in a comparative evaluation of early versus late surgical clipping of ruptured aneurysms that early treatment (within $72 \mathrm{~h}$ after SAH) of patients with a good clinical/neurological condition on admission (WFNS 1-3) leads to a significantly better outcome. A similar trend, without statistical significance, could be detected in patients with worse WFNS grades of 4-5 [94]. Even earlier treatment (within $12 \mathrm{~h}$ ) of SAH patients with WFNS grades IV and $\mathrm{V}$ did not increase the number of dependent survivors [95]. Although there are no good evidence-based data, a general long-lasting consensus exists that ruptured aneurysms of patients with good and moderate clinical SAH grades (WFNS 1-4; Hunt and Hess grade I-IV) should be treated in the early phase after the initial bleeding $(<72 \mathrm{~h}$ after $\mathrm{SAH}$ ). In patients presenting with multiple intracranial aneurysms, i.e. with one ruptured aneurysm causing SAH and several unruptured incidental aneurysms, the ruptured aneurysm is primarily treated. Subsequent treatment of the unruptured incidental aneurysms depends on clinical course after SAH, outcome, age, size, location and configuration of the aneurysm.

Recommendation for Timing of Intervention

- Aneurysm should be treated as early as logistically and technically possible to reduce the risk of rebleeding; if possible it should be aimed to intervene at least within $72 \mathrm{~h}$ after onset of first symptoms

- This decision should not depend on grading (class III, level C)

Neurosurgical Clipping and Endovascular Coiling of Ruptured Aneurysm

In the early beginnings of cerebral aneurysm treatment, surgery was the only approach for RIAs. Starting with proximal ligation of vessels (trapping) like the carotid artery and followed by wrapping of the aneurysm with muscle tissue to strengthen the aneurysm wall to prevent rebleeding, surgical aneurysm treatment is nowadays based on clip occlusion (clipping). Although trap-

Guidelines for Management of

Intracranial Aneurysms and SAH ping and wrapping as sole therapeutic approaches are antiquated, both methods are exceptionally used in combination with other surgical techniques such as aneurysm clipping and/or bypass surgery. Since the development of aneurysm clips, risk of rebleeding significantly decreased. With the establishment of microsurgery, surgical approaches became smaller and less traumatizing. Furthermore, intra-operative indocyanine green angiography and Doppler sonography lead to extra intra-operative quality control [96]. After the invention of detectable platinum coils by G. Guglielmi in 1990, an alternative to surgical clipping developed.

\section{Clip versus Coil}

To compare both therapeutic approaches, clipping and coiling, factors including morbidity, mortality, complete and durable occlusion of the aneurysm, rebleeding (intraand postprocedural aneurysm rupture) and others have to be evaluated: The International Subarachnoid Aneurysm Trial (ISAT) was a randomized controlled trial that compared clipping and coiling (without balloon or stent techniques) [87, 97]. The ISAT study followed the 'uncertainty principle'. The main inclusion criterion of ISAT was that an RIA seemed equally accessible and treatable by either surgical clipping or endovascular coiling ('clinical equipoise'). This inclusion criterion was met by $22.4 \%$ of patients (2,143 of 9,559 patients) with RIAs treated during the study period at the study centres. The remaining $77.6 \%$ of patients suffered from aneurysms which were preferably treated by either coiling or clipping. Those patients were not randomized and were excluded from the study. Besides a highly selected patient cohort, ISAT was also criticized for its high (90\%) proportion of patients with good clinical grades after SAH (Hunt and Hess grades 1-2) and underrepresentation of middle cerebral artery aneurysms, which are often anatomically more difficult to be coiled than aneurysms in other locations. However, for this subpopulation of ruptured aneurysms, which were equally coilable or clippable, ISAT showed that endovascular coiling had an advantage over surgical clipping, with better clinical outcome: absolute risk reduction of death and severe disability after 1 year was $6.9 \%$ in favour of coiling versus clipping, based on the observation that $23.7 \%$ of endovascular-treated patients (compared to $30.6 \%$ of patients after clipping) stayed severely disabled or died after 1 year [97]. The 9 -year followup of ISAT also revealed a reduction in the relative 5-year mortality risk in favour of coiling. No difference could be observed in the amount of independent SAH survivors between the clip (82\%) and coil group (83\%). Both early 
as well as follow-up ISAT analysis showed that patients treated with coiling had a higher rebleeding risk, which was comparable to the risk of suffering SAH from a new aneurysm $[97,98]$. The postoperative risk of rebleeding appears to be associated with the degree of insufficient aneurysm occlusion. Another follow-up study of the patients treated in the ISAT was performed to compare the frequency and consequences of aneurysm recurrence. Retreatment was performed in $17.4 \%$ of patients after primary endovascular coiling and in $3.8 \%$ of patients after neurosurgical clipping. Late retreatment was 6.9 times more likely after coiling. Younger age, larger lumen size, and incomplete occlusion were risk factors for late retreatment after coiling [99]. A post hoc modelling study with mortality as outcome parameter only after coiling and clipping for patients from the ISAT emphasized that no advantage of coil embolization over clip ligation can be assumed for patients younger than 40 years. For these patients clipping might even be the better treatment option in terms of life expectancy [100].

Because of the highly selected aneurysm subpopulation in ISAT, ISAT results cannot be generalized. Recent studies, which consider increasing endovascular treatment during the last years, could not detect any difference in mortality and morbidity between coiling and clipping [101, 102].

The Cerebral Aneurysm Rerupture after Treatment (CARAT) trial was a non-randomized trial that included 1,010 patients with SAH from 1996 to 1998 and followed them up in 2005. Coiling was applied in 299 and clipping in 711 patients. After a mean observation period of 4 years it turned out that the degree of aneurysm occlusion after treatment was strongly associated with risk of rerupture. The overall risk of rerupture tended to be greater after coil embolization compared with surgical clipping, but the difference did not persist after adjustment [103]. Intraprocedural aneurysm rupture and bleeding is common in patients undergoing treatment of RIAs. In the CARAT study patient collective the intraprocedural rupture rate was $5 \%$ with endovascular and $19 \%$ with surgical treatment. The risk of intraprocedural rupture-associated death/disability was doubled in the endovascular group (63\% coiling vs. 31\% clipping) [104].

Further results from 2 randomized trials which recently stopped recruitment are awaited: the HELPS study (HydroCoil Endovascular Aneurysm Occlusion and Packing study) [105], comparing hydrogel-coated coils with standard platinum coils and the Cerecyte Coil study [106], which compares polymer-coated coils with standard platinum coils.
Summarizing the current studies, ruptured aneurysms are complex lesions. The primary goal of treatment should be a complete occlusion of the aneurysm sack to reduce postprocedural rerupture and bleeding. In the case of aneurysms which can be treated equally with clipping or coiling, without stent or balloon (clinical equipoise), endovascular therapy is preferred. However, indications and treatments should be discussed in an interdisciplinary dialogue. In the case of an accompanying space occupying intracerebral hematoma, surgical treatment and clipping is favoured.

As a rough guidance, aneurysms with a wide neck, branching vessels out of the aneurysm sack, middle cerebral artery aneurysms or patients with intracerebral hematoma should preferably be treated by clipping, while aneurysms of the basilar artery or elderly patients (patients $>70$ years, small aneurysm neck, posterior circulation) should be coiled (level B) [104]. Any decision concerning treatment should be interdisciplinary and based on the experience and treatment results of the neurosurgeon and endovascular radiologist, and should be adapted to the individual aspects including parameters such as age, general state of health, location, configuration and size of the aneurysm, as well as the request of the patient. RIAs should be treated in centres that offer high-quality treatment with both modalities.

Recommendation for Interventional Prevention of Rebleeding

- The best mode of intervention should be discussed in an interdisciplinary dialogue between Neurosurgery and Neuroradiology

- Based on this discussion patients should be informed and included in the process of decision making whenever possible

- In cases where the aneurysm appears to be equally effectively treated either by coiling or clipping, coiling is the preferred treatment (class I, level A)

- In general, the decision on whether to clip or coil depends on several factors related to 3 major components:

(1) Patient: age, comorbidity, presence of ICH, SAH grade, aneurysm size, location and configuration, as well as on status of collaterals (class III, level B)

(2) Procedure: competence, technical skills and availability (class III, level B)

(3) Logistics: the grade of interdisciplinarity (class III, level B) In patients with aneurysmal SAH:

- Factors in favour of operative intervention (clipping) are: younger age, presence of space occupying ICH (class II, level

B), and aneurysm-specific factors such as:

- location: middle cerebral artery and pericallosal aneurysm (class III, level B)

- wide aneurysm neck (class III, level B)

- arterial branches exiting directly out of the aneurysmal sack (class III, level B) 
- other unfavourable vascular and aneurysmal configuration for coiling (class IV, level C) [97, 103, 107]

- Factors in favour of endovascular intervention (coiling) are: age above 70 years, (class II, level B), space occupying ICH not present (class II, level B), and

aneurysm-specific factors such as:

- posterior location

- small aneurysm neck

- unilobar shape (class III, level B) [97, 103].

- Elderly patients should not per se be excluded from treatment; decisions whether or not to treat depend on the clinical and physical condition of the patients

Antifibrinolytic Treatment

Antifibrinolytic Drugs. In a Cochrane review including 9 randomized trials of antifibrinolytic drugs in $\mathrm{SAH}$, antifibrinolytic treatment reduced the risk of rebleeding but did not influence death from all causes or a poor outcome [108]. A Swedish trial published after the last update tested a strategy where tranexamic acid was given as soon as SAH had been diagnosed in the local hospital (before the patients were transported) and continued until aneurysm occlusion, which was typically performed within $72 \mathrm{~h}$ [109]. Again the overall outcome did not appreciably improve in patients treated with tranexamic acid, despite an impressive reduction in rebleeding. If this trial is pooled with the 9 other trials included in the Cochrane review, there is still no effect on overall outcome [110]. Further trials with ultra-early and short-term tranexamic acid should be performed before this therapy can be implemented in clinical practice.

Recombinant Factor VIIa. Theoretically, recombinant factor VIIa might prevent rebleeding. An open-label, dose escalation safety study was suspended when the 10th patient developed middle cerebral artery branch occlusion contralateral to the aneurysm [111]. In an uncontrolled series of 18 patients who received an intraoperative dose during surgical occlusion of a ruptured aneurysm, no episodes of rebleeding occurred, but 1 patient developed deep venous thrombosis and 7 an upper extremity venous thrombosis in association with peripherally inserted central catheter lines [111]. At this moment, there is no evidence to support the use of recombinant factor VIIa outside study protocols in patients with SAH.

Statement

- There is currently no medical treatment that improves outcome by reducing rebleeding (class I, level A)

- Results from some small trials that used haemostatic agents suggest further investigations with modified protocols (class II, level C)

Guidelines for Management of

Intracranial Aneurysms and $\mathrm{SAH}$

\section{Hydrocephalus}

Hydrocephalus, defined as a bicaudate index on the CT scan exceeding the 95th percentile for age, occurs in approximately $20 \%$ of patients during the acute phase and in about $10 \%$ during the chronic phase after SAH [112]. Acute hydrocephalus may be caused by obstruction of the CSF flow in the tentorial hiatus by extensive haemorrhage in the perimesencephalic cisterns, or in the ventricles by frank intraventricular haemorrhage $[113,114]$. In about a third of these patients hydrocephalus is asymptomatic, and half of the patients with initial hydrocephalus and impairment of consciousness improve spontaneously within $24 \mathrm{~h}$ [112].

Patients with acute hydrocephalus may be in poor neurological condition immediately after SAH and have dilated ventricles on the CT scan. Such acute hydrocephalus is related to the amount of intraventricular haemorrhage rather than SAH $[112,115]$.

Some neurosurgeons prefer not to use a ventricular drain in these patients immediately as half of them will improve spontaneously and there is a risk of rebleeding and infection. An alternative approach, which can be recommended, is to start immediate external ventricular drainage (keeping intracranial pressure between 10 and $20 \mathrm{~mm} \mathrm{Hg}$ ) in all these patients if there is no other obvious explanation (such as massive ICH) for a reduced level of consciousness (level IV evidence) $[112,116]$. On the other hand, ventriculostomy increases risk for rebleeding and meningitis/ventriculitis [117].

It has been suggested to apply lumbar drainage as a consecutive treatment of external ventricular drainage before shunting in patients with spontaneous ICH when the third and fourth ventricles are free of blood, i.e. communicating hydrocephalus. This approach may be considered as an alternative approach to reduce the frequency of permanent shunts, but is important to pay attention to downward herniation in case of supratentorial swelling and the development of hygroma. So far no prospective clinical trial has proven efficacy of this approach either for spontaneous ICH or patients with SAH $[118,119]$.

Recommendations for Hydrocephalus Management

- In patients with CT-proven hydrocephalus and the third or fourth ventricle filled with blood, an external ventricular drain should be applied; this drain can be used to reduce and monitor pressure and to remove blood; for this last reason the level of evidence is low (GCP)

- In patients who are not sedated and who deteriorate from acute hydrocephalus, lumbar puncture might be considered if the third and fourth ventricle are not filled with blood and supratentorial herniation is prevented (class IV, level C) 
- In patients who are sedated and have CT-proven hydrocephalus, lumbar drainage should be considered if the third and fourth ventricles are not filled with blood (class IV, level C)

- Patients with symptomatic chronic hydrocephalus require ventriculo-peritoneal or ventriculo-atrial shunting (GCP)

\section{Prevention of Delayed Ischemic Deficit}

Pharmacological Prevention/Treatment

A Cochrane review, including 16 trials with 3,361 patients with SAH, found a relative risk of 0.81 ( $95 \%$ CI, $0.72-$ 0.92 ) for death or dependence in the patients treated with calcium antagonists; the corresponding number of patients needed to treat was 19 (95\% CI, 1-51) [120]. For oral nimodipine alone the RR was 0.67 (95\% CI, 0.55-0.81); for other calcium antagonists or intravenous administration of nimodipine the results were not statistically significant. Calcium antagonists reduced the occurrence of secondary ischaemia and showed a favourable trend for case fatality. Although the risk reduction for 'poor outcome' is statistically robust, it depends mainly on a single large trial [121], and therefore the benefits of nimodipine cannot be regarded as being beyond all reasonable doubt. The practical implication is that the regimen in the dominant nimodipine trial (60 mg orally every $4 \mathrm{~h}$ for 3 weeks) is currently regarded as the standard treatment in patients with aneurysmal SAH. If the patient is unable to swallow, the nimodipine tablets should be coarse-grained crushed and washed down a nasogastric tube with normal saline within minutes. Intravenous administration is advocated by the manufacturer and is more expensive, but there is no evidence to support this [120]. Moreover, intravenous administration of nicardipine does not improve outcome [120].

Calcium antagonists have also been applied into the subarachnoid space after surgical occlusion of the aneurysm, but this strategy is of unproven benefit $[122,123]$.

Recommendation on Pharmacological Prevention of Delayed Ischemic Deficit with Nimodipine

- Nimodipine should be administered orally $(60 \mathrm{mg} / 4 \mathrm{~h})$ to prevent delayed ischaemic events (class I, level A)

- In case oral administration is not possible nimodipine should be applied intravenously (GCP)

Other Pharmacological Measures to Prevent Delayed Ischaemic Events

Smaller single-centre studies showed a positive effect of statins on the development of cerebral vasospasm, DCI and mortality. However, the recently published placebocontrolled randomized trial results and meta-analysis did not show any effect of statins on the development or clinical outcome of cerebral vasospasm after SAH $[124,125]$.
Magnesium reduced the frequency of DCI in a dosedependent fashion [126]. The Mash-2 (Magnesium for Aneurysmal Subarachnoid Haemorrhage) trial is a phase-3 controlled trial that randomized $606 \mathrm{SAH}$ patients to intravenous treatment with magnesium sulphate (64 mmol/day) and 597 patients with SAH to placebo. Treatment with magnesium did not improve outcome. A meta-analysis of 7 randomized controlled trials revealed that magnesium treatment is not superior to placebo in the reduction of poor outcome [127].

Recommendation on Other Pharmacological Prevention of Delayed Ischaemic Events

- Magnesium sulphate is not recommended for the prevention of DCI (class I, level A)

- Statins are under study

Hemodynamic Management of Delayed Ischemic

Deficit

Thirty-five years after the first published observation [128], randomized trials on induced hypertension are still lacking, but on the basis of case reports and uncontrolled series many physicians have used induced hypertension and hypervolaemia and seen their patients improve. The risks of deliberately increasing arterial pressure and plasma volume include increased cerebral oedema, haemorrhagic transformation in areas of infarction [129], reversible leucencephalopathy [130], myocardial infarction and congestive heart failure.

Statement on Hemodynamic Management of Delayed Ischaemic Deficit

- There is no evidence from controlled studies for induced hypertension or hypervolaemia to improve outcome in patients with delayed ischaemic deficit (class IV, level C)

\section{SAH without Aneurysm}

\section{Epidemiology and Definition}

In about $15 \%$ of non-traumatic SAH no bleeding source is found by DSA (see Diagnosis). In these cases we differentiate between perimesencephalic and nonperimesencephalic location of the SAH, because these determine further therapeutic approach.

\section{Perimesencephalic SAH}

The diagnosis 'perimesencephalic SAH' (PMSAH) is defined by exclusion of an aneurysmatic bleeding and typical 
location of blood within the perimesencephalic and prepontine cisterns (i.e. no blood in sylvic and interhemispheric fissure) $[131,132]$. Though blood sedimentation in the ventricles may occur, occlusion of ventricles or parenchymal bleeding is not in line with the definition of PMSAH.

Imaging alone is not sufficient to make the diagnosis of PMSAH, because bleeding sources may be the cause of this bleeding, as vertebrobasilar aneurysm or arteriovenous malformation. The risk of making the diagnosis, on the one hand, is determined by the overall annual incidence rates for SAH and PMSAH: 8.7 (95\% CI, 7.9-9.5) and 0.5 (95\% CI, 0.3-0.7) per 100,000 persons aged $\geq 18$, respectively [133]. On the other hand stands the risk (2$3 \%)$ of intra-arterial DSA $[134,135]$. At the same time CTA and MRA were found to have high sensitivity of excluding aneurysmal bleedings in PMSAH [136, 137]. Whether this justifies the decision not to perform DSA in PMSAH still needs to be proven by larger prospective studies. However, repeat angiography in the case of negative baseline DSA after PMSAH is not recommended, since the procedural risk outweighs the chance of finding an aneurysm [131, 132, 138, 139].

Clinically, PMSAH seems to present milder with less severe outcome than diffuse SAH without aneurysm [140]. The occurrence of vasospasm and the association with DCI may be low [141-143]. The prophylactic application of nimodipine (and other calcium antagonists) cannot be recommended until more studies demonstrate the relevance of DCI in PMSAH.

Apart from DCI and rebleeding, other complications like hydrocephalus, hyponatremia and electrographic changes may be as frequent in PMSAH as they are in aneurysmal SAH [144]. These complications should be treated as recommended above.

Rebleeding seems not to play a role in long-term prognosis and survival of PMSAH is not decreased [132, 139, 145]. All these observations indicate that the cause of PMSAH is not arterial bleeding, but may be due to variants of infratentorial venous drainage [146].

\section{Non-Perimesencephalic SAH}

Almost all studies that deal with non-perimesencephalic SAH with no bleeding source in the baseline DSA are retrospective [141, 147-151]. However, the frequency of positive findings in a follow-up angiography in these studies ranged between 5 and 35\%. Therefore, repeat angiography is recommended in non-perimesencephalic SAH without bleeding source.

Guidelines for Management of Intracranial Aneurysms and $\mathrm{SAH}$
Table 3. Rare causes of non-traumatic $\mathrm{SAH}$

Infectious arterial vasculitis

Mycotic (infectious) aneurysm

Meningo-vascular lues

Lyme disease

Gnathostomiasis (Gnathostoma spinigerum)

Immune vasculitis

Primary CNS angiitis

Polyarteritis nodosa

Wegener's vasculitis

Churg-Strauss syndrome

Behçet's disease

Other cerebrovascular diseases

Arteriovenous angioma

Dural arteriovenous fistula

Spinal arterial aneurysm

Intracranial arterial dissection

Venous sinus thrombosis

Cerebral amyloid angiopathy

Moyamoya disease

Sickle cell anaemia

Intracranial und intraspinal tumour

Anticoagulants und thrombolytic therapy

Cocaine

\section{Non-Traumatic SAH of Other Causes}

Non-traumatic SAH can be caused by various other, non-aneurysmatic causes (table 3). Diagnoses and treatment of these SAH cases need to be performed according specifically to the underlying cause.

Recommendation on Diagnostic Procedure in SAH without Aneurysm

- In patients with PMSAH a DSA should only be performed if the CTA was not considered to be sufficient or if there is doubt on the perimesencephalic pattern of the SAH (class II, level B)

- In the case of non-perimesencephalic location of the bleeding with typical pattern of SAH, CTA or DSA should be repeated not earlier than 3 weeks after the initial bleeding if there are no other therapeutic indications to perform the studies earlier (class III, level B)

\section{Unruptured Intracranial Aneurysms}

\section{Epidemiology}

Since SAH is still a serious disease with high rates of case fatality and morbidity, unruptured aneurysms, when incidentally discovered or found in connection with diagnosis of ruptured aneurysm (multiple aneurysm cases), have been operated on for decades in western countries. Unruptured aneurysms are usually classified as follows: 
Table 4. Risk of rupture of unruptured intracranial aneurysm

\begin{tabular}{lcllll}
\hline Study & $\begin{array}{l}\text { Patients } \\
\mathrm{n}\end{array}$ & $\begin{array}{l}\text { SAHs } \\
\mathrm{n}\end{array}$ & $\begin{array}{l}\text { Follow-up } \\
\text { years }\end{array}$ & $\begin{array}{l}\text { Incidence/ } \\
\text { year } \\
\%\end{array}$ & $\begin{array}{l}\text { Risk } \\
\text { factors }\end{array}$ \\
\hline ISUIA-03 & 1,692 & 51 & 6,544 & 0.8 & 1,2 \\
Juvela-00-03 & 142 & 34 & 2,577 & 1.3 & $1,3,4$ \\
\hline
\end{tabular}

Risk factors: 1 = aneurysm diameter, 2 = aneurysm location, $3=$ cigarette smoking and $4=$ patient age.

asymptomatic incidental aneurysms, symptomatic aneurysms, and unruptured (additional) aneurysms in SAH patients (multiple aneurysm cases). By occlusion of an unruptured aneurysm, the high case fatality and morbidity associated with a possible severe $\mathrm{SAH}$ can be eliminated by preventive surgical or endovascular intervention. However, natural history, risks of endovascular treatment and surgery of UIAs, and risk factors for rupture remain unclear as studies with sufficient numbers of patients and follow-up years are lacking.

Thus far, there are only few prospective follow-up studies and several small retrospective ones evaluating the natural history of UIAs. Furthermore, patient populations of different studies have been more or less selected for important predictive factors, surgery and patient age.

Table 4 shows cohorts of the 2 largest published prospective studies of rupture risk of UIAs (class II/III, level $B$ recommendation) [41-43]. The prospective part of The International Study of Unruptured Intracranial Aneurysms (ISUIA; patient enrolment in 61 centres between 1991 and 1998) shows somewhat different results compared with those of the retrospective part of ISUIA (in 53 centres between 1970 and 1991) [41, 152]. In the prospective study, overall incidence of aneurysm rupture was higher ( 0.8 vs. $0.3 \%$ per year), risk for rupture of vertebrobasilar aneurysms was lower (relative risk 2.3 vs. 5.1-13.8 compared with other aneurysms), mean follow-up time per patient was shorter ( 3.9 vs. 8.3 years), there was a lower limit of aneurysm diameter for very low risk for rupture in patients without a prior SAH ( $<7 \mathrm{vs.}<10 \mathrm{~mm})$, and there was a non-significant direct association between patient age and aneurysm rupture risk compared with the results obtained in the retrospective study.

Although ISUIA included a large number of patients, differences between results of prospective and retrospective ISUIA studies suggest selection bias. Therefore, results of ISUIA may be difficult to generalize to patient populations with unruptured aneurysms, and the results should be noted with some caution. In addition, among adults aged $>30$ years, annual incidence rates of SAH are at least 30-40 per 100,000, and estimated aneurysm prevalence rates for adults are $2-5 \%[9,11,12,153]$. Thus, expected rupture incidence of unruptured aneurysms in the general adult population should be at least $1 \%$ per year. Rupture risks reported by the ISUIA may be somewhat underestimated, which is also suggested by the fact that the majority of the ruptured aneurysms are $<10 \mathrm{~mm}$ in diameter.

Patients of the ISUIA were collected from the time period when UIAs were operated on to a great extent, particularly in patients of working age, as was seen in the high proportion of patients (58\%) who were operated on with either open or endovascular surgery [41]. Patients whose unruptured aneurysms were operated on with open surgery were younger and significantly $(\mathrm{p}<0.01)$ more likely current cigarette smokers than those with no surgery [41]. There were also several other significant differences between groups of open surgery, endovascular treatment and no treatment concerning the most important predicting factors for rupture or outcome after possible treatment. These include aneurysm size and location as well as different medical or behavioural factors.

The results of a prospective natural history study of unruptured aneurysms from the Helsinki University Central Hospital (patient enrolment in 1 centre between 1956 and 1978) have been reported several times since 1960 as the number of patients and follow-up years increased with elapsed time $[23,42,153,154]$. This cohort had a long-term follow-up (mean 18.2, median 19.7 years per patient), had no surgical selection and had a complete follow-up of cases with unruptured aneurysms, but the number of patients $(n=142)$ was modest compared with that of ISUIA and almost all were patients of working age, had high prevalence of smoking, and had multiple aneurysms with the ruptured aneurysm clipped at start of follow-up $[42,153]$. So, these results cannot necessarily be generalized to those patients of advanced age who have incidentally found aneurysms. Patients with incidental aneurysms are now increasingly found on either MRA or 3D CTA. On the other hand, the annual rupture rate of $1.3 \%$ (95\% CI, $0.9-1.7 \%)$ was similar to that of smaller previously published retrospective patient series (1-3\%) and remained almost constant for 25 years after diagnosis. Significant risk factors for aneurysm rupture were cigarette smoking (tested also as a time-dependent covariate), aneurysm diameter (linear association) and age, inversely [42]. High systolic blood pressure values and 
long-term hypertension during follow-up predicted fatal aneurysm rupture [23]. Although patients with multiple aneurysms have an increased risk for aneurysm formation, they do not have an increased risk for rupture of unruptured aneurysm compared with those with a single unruptured aneurysm $[41,42,152,153]$.

When deciding means of treatment of unruptured aneurysm, one must take into account not only the maximum diameter of the aneurysm $[41,42]$ but also patient age [42], location of aneurysm (posterior communicating and vertebrobasilar aneurysms may have higher rupture risk) [41], history of hypertension [23] and previous SAH (not an independent risk factor for rupture) [41], as well as cigarette smoking [42]. In the prospective part of ISUIA, risks of treatment were similar in the open surgical and endovascular treatment groups [41]. On the other hand, patients treated more commonly with endovascular coiling procedures than with open surgery were those who also had higher risks for poor outcome after operative treatment (older age, larger aneurysms, more frequently basilar tip aneurysms). However, aneurysmal obliteration with endovascular treatment was complete in only $51 \%$ of cases, and durability of treatment remained unknown due to a short follow-up time. Although endovascular coiling has been shown to be effective in the prevention of rebleeding after aneurysmal SAH [97], its use for the treatment of unruptured aneurysms is not so evident, particularly in young adults, since benefit of treatment cannot be seen until a follow-up of several decades. Incomplete coiling of large aneurysms (failures of organization of intraaneurysm thrombus, complete fibrous aneurysm obliteration and endothelization of aneurysm orifice) can lead to a recanalization and unexpected growth and rupture of aneurysm during follow-up [155], and these aneurysms are difficult to treat later with open surgery. However, coiling of unruptured aneurysms may be useful in an older patient with a basilar tip aneurysm which is not large $(<12 \mathrm{~mm})$ and has a narrow neck, as well as in those who have had previous cerebral ischaemia $[41,155]$.

Risks of open surgery of unruptured aneurysms of the ISUIA (mortality $1.5-2.3 \%$, disability $10-12 \%$ ) [41] were similar to those obtained in a meta-analysis (overall mortality $2.6 \%$, permanent disability $10.9 \%$ ) [156]. Poor outcome with open surgery was independently predicted by aneurysm size, posterior circulation aneurysm, advanced age and previous ischaemic cerebrovascular disease [41]. Poor outcome with endovascular treatment was independently predicted by aneurysm size and posterior circulation aneurysm [41]. In the ISUIA, $11 \%$ of patients with aneurysm occlusion by open surgery had cerebral infarc- tion, while $5 \%$ of those with endovascular aneurysm occlusion had such a lesion. However, durability and overall treatment risks of endovascular treatment are unknown in a long-term follow-up. Thus, open surgery of unruptured aneurysms should continue, at least by those neurosurgeons having postoperative infarct risk of $\leq 5 \%$ in aneurysm surgery.

In the meta-analysis, technically difficult aneurysms were overrepresented [giant aneurysms $(>25 \mathrm{~mm}) 27 \%$, posterior circulation aneurysms 30\%] [156]. Thus, these favourable results were probably affected by publication bias. Authors calculated the following unfavourable results for specific aneurysm groups: anterior non-giant aneurysms, mortality $0.8 \%$ and morbidity $1.9 \%$; posterior non-giant aneurysms, 3.0 and $12.9 \%$; anterior giant aneurysms 7.4 and $26.9 \%$, and posterior giant aneurysms 9.6 and $37.9 \%$, respectively [156].

As estimated from the above-mentioned studies, operative treatment should be considered for all unruptured aneurysms in patients aged $<50$ to 60 years (open surgery) as well as perhaps for aneurysms of $\geq 7 \mathrm{~mm}$ in diameter in older patients (open surgery or endovascular treatment) if there are no contraindications and patients have no serious pre-existing diseases [41, 42]. Advanced age and history of ischaemic cerebrovascular disease favour the use of endovascular treatment [41].

Patients with symptomatic aneurysms should be candidates for the treatment of aneurysm occlusion irrespective of age since symptoms may be due to a minor leak or growing aneurysm that predicts a major rupture. Final techniques of treatment of unruptured aneurysms depend on the experience of neurosurgeons and neuroradiologists of each centre. Finally, cessation of cigarette smoking and active treatment of hypertension are important for patients with unruptured aneurysms irrespective of the methods of treatment of these lesions [23, 42].

\section{Treatment}

\section{Clipping or Coiling}

Statement on Intervention in UIA

- Although endovascular procedures might be associated with less immediate risk, the long-term risk and durability of treatment are not known and data from prolonged follow-up of treated patients are needed

- Data indicate there exists a state of clinical equipoise in the management of a significant proportion of UIAs; this impression is reinforced by the broad variation in management for UIAs in the participating institutions
Guidelines for Management of Intracranial Aneurysms and $\mathrm{SAH}$
Cerebrovasc Dis 2013;35:93-112 DOI: $10.1159 / 000346087$ 
Recommendation on Intervention in UIA

- The larger the aneurysm the higher the chance of rupture (class II, level B)

- Considering risk (procedural risk, range 5-50\%, vs. spontaneous rupture risk, $0-10 \%$, per year) and benefit (life expectancy with or without minor deficit), the decision for or against intervention is a decision of the individual case taking into account patient-dependent factors (age, cigarette smoking and perhaps rupture from other aneurysm), aneurysmal factors (size, location), and the assumed risk of the intervention; therefore, the decision should be based on a multidisciplinary discussion of the individual case (class III, level C)

\section{References}

1 Connolly ES Jr, Rabinstein AA, Carhuapoma JR, Derdeyn CP, Dion J, Higashida RT, Hoh BL, Kirkness CJ, Naidech AM, Ogilvy CS, Patel AB, Thompson BG, Vespa P: Guidelines for the management of aneurysmal subarachnoid hemorrhage: a guideline for healthcare professionals from the American Heart Association/American Stroke Association. Stroke 2012;43:1711-1737.

-2 Brainin M, Barnes M, Baron JC, Gilhus NE, Hughes R, Selmaj K, Waldemar G: Guidance for the preparation of neurological management guidelines by EFNS scientific task forces - revised recommendations 2004. Eur J Neurol 2004;11:577-581.

-3 Hunt WE, Hess RM: Surgical risk as related to time of intervention in the repair of intracranial aneurysms. J Neurosurg 1968;28:14-20.

-4 Lindsay KW, Teasdale G, Knill-Jones RP, Murray L: Observer variability in grading patients with subarachnoid hemorrhage. J Neurosurg 1982;56:628-633.

-5 World Federation of Neurological Surgeons Committee: Report of World Federation of Neurological Surgeons Committee on a Universal Subarachnoid Hemorrhage Grading Scale. J Neurosurg 1988;68:985-986.

6 Oshiro EM, Walter KA, Piantadosi S, Witham TF, Tamargo RJ: A new subarachnoid hemorrhage grading system based on the Glasgow Coma Scale: a comparison with the Hunt and Hess and World Federation of Neurological Surgeons Scales in a clinical series. Neurosurgery 1997;41:140-147, discussion pp 147-148.

7 Takagi K, Tamura A, Nakagomi T, Nakayama H, Gotoh O, Kawai K, Taneda M, Yasui N, Hadeishi H, Sano K: How should a subarachnoid hemorrhage grading scale be determined? A combinatorial approach based solely on the Glasgow Coma Scale. J Neurosurg 1999;90:680-687.

8 van Heuven AW, Dorhout Mees SM, Algra A, Rinkel GJ: Validation of a prognostic subarachnoid hemorrhage grading scale derived directly from the Glasgow Coma Scale. Stroke 2008;39:1347-1348.

$\checkmark 9$ de Rooij NK, Linn FH, van der Plas JA, Algra A, Rinkel GJ: Incidence of subarachnoid haemorrhage: a systematic review with emphasis on region, age, gender and time trends. J Neurol Neurosurg Psychiatry 2007;78:1365-1372.
10 Fogelholm R, Hernesniemi J, Vapalahti M: Impact of early surgery on outcome after aneurysmal subarachnoid hemorrhage. A populationbased study. Stroke 1993;24:1649-1654.

11 Rinkel GJ, Djibuti M, Algra A, van Gijn J: Prevalence and risk of rupture of intracranial aneurysms: a systematic review. Stroke 1998;29:251-256.

12 Numminen H, Kotila M, Waltimo O, Aho K, Kaste M: Declining incidence and mortality rates of stroke in Finland from 1972 to 1991. Results of three population-based stroke registers. Stroke 1996;27:1487-1491.

13 Pakarinen S: Incidence, aetiology, and prognosis of primary subarachnoid haemorrhage. A study based on 589 cases diagnosed in a defined urban population during a defined period. Acta Neurol Scand 1967; 43(suppl 29):1-128.

14 Hop JW, Rinkel GJ, Algra A, van Gijn J: Casefatality rates and functional outcome after subarachnoid hemorrhage: a systematic review. Stroke 1997;28:660-664.

15 Huang J, van Gelder JM: The probability of sudden death from rupture of intracranial aneurysms: a meta-analysis. Neurosurgery 2002;51:1101-1105, discussion pp 1105-1107.

16 Phillips LH 2nd, Whisnant JP, O’Fallon WM, Sundt TM Jr: The unchanging pattern of subarachnoid hemorrhage in a community. Neurology 1980;30:1034-1040.

17 Jane JA, Kassell NF, Torner JC, Winn HR: The natural history of aneurysms and arteriovenous malformations. J Neurosurg 1985; 62:321-323.

18 Winn HR, Richardson AE, O’Brien W, Jane JA: The long-term prognosis in untreated cerebral aneurysms. II. Late morbidity and mortality. Ann Neurol 1978;4:418-426.

$\checkmark 19$ Nishioka H, Torner JC, Graf CJ, Kassell NF, Sahs AL, Goettler LC: Cooperative study of intracranial aneurysms and subarachnoid hemorrhage: a long-term prognostic study. II. Ruptured intracranial aneurysms managed conservatively. Arch Neurol 1984;41: 1142-1146

20 Inagawa T: Trends in incidence and case fatality rates of aneurysmal subarachnoid hemorrhage in Izumo City, Japan, between 1980-1989 and 1990-1998. Stroke 2001;32: 1499-1507.
21 Nieuwkamp DJ, Setz LE, Algra A, Linn FH, de Rooij NK, Rinkel GJ: Changes in case fatality of aneurysmal subarachnoid haemorrhage over time, according to age, sex, and region: a meta-analysis. Lancet Neurol 2009; 8:635-642.

22 Juvela S: Alcohol consumption as a risk factor for poor outcome after aneurysmal subarachnoid haemorrhage. BMJ 1992;304: 1663-1667.

23 Juvela S: Prehemorrhage risk factors for fatal intracranial aneurysm rupture. Stroke 2003; 34:1852-1857.

24 Kassell NF, Torner JC, Haley EC, Jane JA, Adams HP, Kongale GL: The International Cooperative Study on the timing of aneurysm surgery. Part 1 . Overall management results. J Neurosurg 1990;73:18-36.

25 Lanzino G, Kassell NF, Germanson T, Truskowski L, Alves W: Plasma glucose levels and outcome after aneurysmal subarachnoid hemorrhage. J Neurosurg 1993;79:885-891.

-26 Koffijberg H, Buskens E, Granath F, Adami J, Ekbom A, Rinkel GJ, Blomqvist P: Subarachnoid haemorrhage in Sweden 19872002: regional incidence and case fatality rates. J Neurol Neurosurg Psychiatry 2008; 79:294-299.

27 Weir BK, Kongable GL, Kassell NF, Schultz JR, Truskowski LL, Sigrest A: Cigarette smoking as a cause of aneurysmal subarachnoid hemorrhage and risk for vasospasm: a report of the Cooperative Aneurysm Study. J Neurosurg 1998;89:405-411.

28 Moussouttas M, Huynh TT, Khoury J, Lai EW, Dombrowski K, Pello S, Pacak K: Cerebrospinal fluid catecholamine levels as predictors of outcome in subarachnoid hemorrhage. Cerebrovasc Dis 2012;33:173-181.

29 Shim JH, Yoon SM, Bae HG, Yun IG, Shim JJ, Lee KS, Doh JW: Which treatment modality is more injurious to the brain in patients with subarachnoid hemorrhage? Degree of brain damage assessed by serum $\$ 100$ protein after aneurysm clipping or coiling. Cerebrovasc Dis 2012;34:38-47.

30 Juvela S, Siironen J, Kuhmonen J: Hyperglycemia, excess weight, and history of hypertension as risk factors for poor outcome and cerebral infarction after aneurysmal subarachnoid hemorrhage. J Neurosurg 2005; 102:998-1003. 
-31 Dorhout Mees SM, van Dijk GW, Algra A, 45 Wang PS, Longstreth WT Jr, Koepsell TD: Kempink DR, Rinkel GJ: Glucose levels and outcome after subarachnoid hemorrhage. Neurology 2003;61:1132-1133.

32 Juvela S, Siironen J: D-dimer as an independent predictor for poor outcome after aneurysmal subarachnoid hemorrhage. Stroke 2006;37:1451-1456.

- 33 Meyer B, Ringel F, Winter Y, Spottke A, Gharevi N, Dams J, Balzer-Geldsetzer M, Mueller IK, Klockgether T, Schramm J, Urbach H, Dodel R: Health-related quality of life in patients with subarachnoid haemorrhage. Cerebrovasc Dis 2010;30:423-431.

- 34 Feigin VL, Rinkel GJ, Lawes CM, Algra A, Bennett DA, van Gijn J, Anderson CS: Risk factors for subarachnoid hemorrhage: an updated systematic review of epidemiological studies. Stroke 2005;36:2773-2780.

35 Kissela BM, Sauerbeck L, Woo D, Khoury J, Carrozzella J, Pancioli A, Jauch E, Moomaw CJ, Shukla R, Gebel J, Fontaine R, Broderick $\mathrm{J}$ : Subarachnoid hemorrhage: a preventable disease with a heritable component. Stroke 2002;33:1321-1326.

-36 Juvela S, Hillbom M, Numminen H, Koskinen P: Cigarette smoking and alcohol consumption as risk factors for aneurysmal subarachnoid hemorrhage. Stroke 1993;24: 639-646.

-37 Bonita R: Cigarette smoking, hypertension and the risk of subarachnoid hemorrhage: a population-based case-control study. Stroke 1986;17:831-835.

-38 Longstreth WT Jr, Nelson LM, Koepsell TD, van Belle G: Cigarette smoking, alcohol use, and subarachnoid hemorrhage. Stroke 1992; 23:1242-1249.

-39 Ruigrok YM, Buskens E, Rinkel GJ: Attributable risk of common and rare determinants of subarachnoid hemorrhage. Stroke 2001; 32:1173-1175.

40 Juvela S: Risk factors for multiple intracranial aneurysms. Stroke 2000;31:392-397.

41 Wiebers DO, Whisnant JP, Huston J 3rd, Meissner I, Brown RD Jr, Piepgras DG, Forbes GS, Thielen K, Nichols D, O’Fallon WM, Peacock J, Jaeger L, Kassell NF, Kongable-Beckman GL, Torner JC: Unruptured intracranial aneurysms: natural history, clinical outcome, and risks of surgical and endovascular treatment. Lancet 2003;362:103-110.

-42 Juvela S, Porras M, Poussa K: Natural history of unruptured intracranial aneurysms: probability of and risk factors for aneurysm rupture. J Neurosurg 2000;93:379-387.

43 Juvela S, Poussa K, Porras M: Factors affecting formation and growth of intracranial aneurysms: a long-term follow-up study. Stroke 2001;32:485-491.

-44 Wermer MJ, van der Schaaf IC, Velthuis BK, Algra A, Buskens E, Rinkel GJ: Follow-up screening after subarachnoid haemorrhage: frequency and determinants of new aneurysms and enlargement of existing aneurysms. Brain 2005;128:2421-2429. Subarachnoid hemorrhage and family history. A population-based case-control study. Arch Neurol 1995;52:202-204.

46 Ronkainen A, Hernesniemi J, Ryynanen M: Familial subarachnoid hemorrhage in east Finland, 1977-1990. Neurosurgery 1993;33: 787-796, discussion pp 796-797.

47 Ronkainen A, Miettinen H, Karkola K, Papinaho S, Vanninen R, Puranen M, Hernesniemi J: Risk of harboring an unruptured intracranial aneurysm. Stroke 1998;29:359-362.

48 Carmelli D, Swan GE, Robinette D, Fabsitz R: Genetic influence on smoking - a study of male twins. N Engl J Med 1992;327:829-833.

49 Broderick JP, Viscoli CM, Brott T, Kernan WN, Brass LM, Feldmann E, Morgenstern LB, Wilterdink JL, Horwitz RI: Major risk factors for aneurysmal subarachnoid hemorrhage in the young are modifiable. Stroke 2003;34:1375-1381.

50 Bromberg JE, Rinkel GJ, Algra A, van den Berg UA, Tjin ATML, van Gijn J: Hypertension, stroke, and coronary heart disease in relatives of patients with subarachnoid hemorrhage. Stroke 1996;27:7-9.

51 Sundquist J, Li X, Sundquist K, Hemminki $\mathrm{K}$ : Risks of subarachnoid hemorrhage in siblings: a nationwide epidemiological study from Sweden. Neuroepidemiology 2007;29: 178-184.

52 Schievink WI, Schaid DJ, Michels VV, Piepgras DG: Familial aneurysmal subarachnoid hemorrhage: a community-based study. Neurosurg 1995;83:426-429.

53 Raaymakers TW: Aneurysms in relatives of patients with subarachnoid hemorrhage: frequency and risk factors. MARS Study Group. Magnetic resonance angiography in relatives of patients with subarachnoid hemorrhage. Neurology 1999;53:982-988.

54 Greebe P, Bromberg JE, Rinkel GJ, Algra A, van Gijn J: Family history of subarachnoid haemorrhage: supplemental value of scrutinizing all relatives. J Neurol Neurosurg Psychiatry 1997;62:273-275.

55 Bromberg JE, Rinkel GJ, Algra A, Greebe P, Beldman T, van Gijn J: Validation of family history in subarachnoid hemorrhage. Stroke 1996;27:630-632.

56 Bromberg JE, Rinkel GJ, Algra A, Greebe P, van Duyn CM, Hasan D, Limburg $M$, ter Berg HW, Wijdicks EF, van Gijn J: Subarachnoid haemorrhage in first and second degree relatives of patients with subarachnoid haemorrhage. BMJ 1995;311:288-289.

57 Bor AS, Rinkel GJ, Adami J, Koffijberg H, Ekbom A, Buskens E, Blomqvist P, Granath F: Risk of subarachnoid haemorrhage according to number of affected relatives: a population based case-control study. Brain 2008;131:2662-2665.

58 Tokuda Y, Stein GH: Serum lipids as protective factors for subarachnoid hemorrhage. J Clin Neurosci 2005;12:538-541.
9 Tsutsumi K, Ueki K, Morita A, Usui M, Kirino $\mathrm{T}$ : Risk of aneurysm recurrence in patients with clipped cerebral aneurysms: results of long-term follow-up angiography. Stroke 2001;32:1191-1194.

60 Wermer MJ, Koffijberg H, van der Schaaf IC: Effectiveness and costs of screening for aneurysms every 5 years after subarachnoid hemorrhage. Neurology 2008;70:2053-2062.

61 van der Wee N, Rinkel GJ, Hasan D, van Gijn J: Detection of subarachnoid haemorrhage on early CT: is lumbar puncture still needed after a negative scan? J Neurol Neurosurg Psychiatry 1995;58:357-359.

62 Vermeulen M, van Gijn J: The diagnosis of subarachnoid haemorrhage. J Neurol Neurosurg Psychiatry 1990;53:365-372.

63 Fifi JT, Meyers PM, Lavine SD, Cox V, Silverberg L, Mangla S, Pile-Spellman J: Complications of modern diagnostic cerebral angiography in an academic medical center. J Vasc Interv Radiol 2009;20:442-447.

64 Dammert S, Krings T, Moller-Hartmann W, Ueffing E, Hans FJ, Willmes K, Mull M, Thron A: Detection of intracranial aneurysms with multislice CT: comparison with conventional angiography. Neuroradiology 2004;36:427-434.

65 White PM, Teasdale EM, Wardlaw JM, Easton V: Intracranial aneurysms: CT angiography and MR angiography for detection prospective blinded comparison in a large patient cohort. Radiology 2001;219:739-749.

-66 Agid R, Andersson T, Almqvist H, Willinsky RA, Lee SK, terBrugge KG, Farb RI, Soderman M: Negative CT angiography findings in patients with spontaneous subarachnoid hemorrhage: when is digital subtraction angiography still needed? AJNR Am J Neuroradiol 2010;31:696-705.

67 Sarker SJ, Heuschmann PU, Burger I, Wolfe CD, Rudd AG, Smeeton NC, Toschke AM: Predictors of survival after haemorrhagic stroke in a multi-ethnic population: the South London Stroke Register (SLSR). J Neurol Neurosurg Psychiatry 2008;79:260-265.

68 Frontera JA, Fernandez A, Schmidt JM, Claassen J, Wartenberg KE, Badjatia N, Parra A, Connolly ES, Mayer SA: Impact of nosocomial infectious complications after subarachnoid hemorrhage. Neurosurgery 2008; 62:80-87, discussion p 87.

69 Wartenberg KE, Schmidt JM, Claassen J, Temes RE, Frontera JA, Ostapkovich N, Parra A, Connolly ES, Mayer SA: Impact of medical complications on outcome after subarachnoid hemorrhage. Crit Care Med 2006; 34:617-623, quiz p 624.

70 Bilotta F, Spinelli A, Giovannini F, Doronzio A, Delfini R, Rosa G: The effect of intensive insulin therapy on infection rate, vasospasm, neurologic outcome, and mortality in neurointensive care unit after intracranial aneurysm clipping in patients with acute subarachnoid hemorrhage: a randomized prospective pilot trial. J Neurosurg Anesthesiol 2007;19:156-160.
Guidelines for Management of Intracranial Aneurysms and $\mathrm{SAH}$
Cerebrovasc Dis 2013;35:93-112 DOI: $10.1159 / 000346087$ 
71 Dorhout Mees SM, Luitse MJ, van den Bergh WM, Rinkel GJ: Fever after aneurysmal subarachnoid hemorrhage: relation with extent of hydrocephalus and amount of extravasated blood. Stroke 2008;39:2141-2143.

72 Todd MM, Hindman BJ, Clarke WR, Torner JC: Mild intraoperative hypothermia during surgery for intracranial aneurysm. N Engl J Med 2005;352:135-145.

-73 Wijdicks EF, Vermeulen M, Murray GD, Hijdra A, van Gijn J: The effects of treating hypertension following aneurysmal subarachnoid hemorrhage. Clin Neurol Neurosurg 1990;92:111-117.

74 Varon J, Marik PE: Clinical review: the management of hypertensive crises. Crit Care 2003;7:374-384.

-75 Siironen J, Juvela S, Varis J, Porras M, Poussa K, Ilveskero S, Hernesniemi J, Lassila R: No effect of enoxaparin on outcome of aneurysmal subarachnoid hemorrhage: a randomized, double-blind, placebo-controlled clinical trial. J Neurosurg 2003;99:953-959.

-76 Juvela S, Siironen J, Varis J, Poussa K, Porras M: Risk factors for ischemic lesions following aneurysmal subarachnoid hemorrhage. J Neurosurg 2005;102:194-201.

-77 Dickinson LD, Miller LD, Patel CP, Gupta SK: Enoxaparin increases the incidence of postoperative intracranial hemorrhage when initiated preoperatively for deep venous thrombosis prophylaxis in patients with brain tumors. Neurosurgery 1998;43: 1074-1081.

78 Black PM, Baker MF, Snook CP: Experience with external pneumatic calf compression in neurology and neurosurgery. Neurosurgery 1986;18:440-444.

-79 Naccarato M, Chiodo Grandi F, Dennis M, Sandercock PA: Physical methods for preventing deep vein thrombosis in stroke. Cochrane Database Syst Rev 2010:CD001922.

-80 Lacut K, Bressollette L, Le Gal G, Etienne E, De Tinteniac A, Renault A, Rouhart F, Besson G, Garcia JF, Mottier D, Oger E: Prevention of venous thrombosis in patients with acute intracerebral hemorrhage. Neurology 2005;65:865-869.

81 Butzkueven H, Evans AH, Pitman A, Leopold C, Jolley DJ, Kaye AH, Kilpatrick CJ, Davis SM: Onset seizures independently predict poor outcome after subarachnoid hemorrhage. Neurology 2000;55:1315-1320.

-82 Lin CL, Dumont AS, Lieu AS, Yen CP, Hwang SL, Kwan AL, Kassell NF, Howng SL: Characterization of perioperative seizures and epilepsy following aneurysmal subarachnoid hemorrhage. J Neurosurg 2003;99:978985.

83 Claassen J, Jette N, Chum F, Green R, Schmidt M, Choi H, Jirsch J, Frontera JA, Connolly ES, Emerson RG, Mayer SA, Hirsch LJ: Electrographic seizures and periodic discharges after intracerebral hemorrhage. Neurology 2007;69:1356-1365.
84 Dennis LJ, Claassen J, Hirsch LJ, Emerson RG, Connolly ES, Mayer SA: Nonconvulsive status epilepticus after subarachnoid hemorrhage. Neurosurgery 2002;51:1136-1143, discussion $\mathrm{p} 1144$.

85 Claassen J, Hirsch LJ, Frontera JA, Fernan$\operatorname{dez}$ A, Schmidt M, Kapinos G, Wittman J, Connolly ES, Emerson RG, Mayer SA: Prognostic significance of continuous EEG monitoring in patients with poor-grade subarachnoid hemorrhage. Neurocrit Care 2006;4:103-112.

86 Kull LL, Emerson RG: Continuous EEG monitoring in the intensive care unit: technical and staffing considerations. J Clin Neurophysiol 2005;22:107-118.

87 Molyneux AJ, Kerr RS, Yu L-M, Clarke M, Sneade M, Yarnold JA, Sandercock P, International Subarachnoid Aneurysm Trial (ISAT) Collaborative Group: International Subarachnoid Aneurysm Trial (ISAT) of neurosurgical clipping versus endovascular coiling in 2,143 patients with ruptured intracranial aneurysms: a randomised comparison of effects on survival, dependency, seizures, rebleeding, subgroups, and aneurysm occlusion. Lancet 2005;366:809-817.

88 Foy PM, Chadwick DW, Rajgopalan N, Johnson AL, Shaw MD: Do prophylactic anticonvulsant drugs alter the pattern of seizures after craniotomy? J Neurol Neurosurg Psychiatry 1992;55:753-757.

89 Rosengart AJ, Huo JD, Tolentino J, Novakovic RL, Frank JI, Goldenberg FD, Macdonald RL: Outcome in patients with subarachnoid hemorrhage treated with antiepileptic drugs. J Neurosurg 2007;107:253-260.

-90 Feigin VL, Anderson NE, Rinkel GJE, Algra A, van Gjn J, Bennett DA: Corticosteroids for aneurysmal subarachnoid hemorrhage and primary intracerebral hemorrhage. Cochrane Database of Syst Rev 2005:CD004583.

91 Katayama Y, Haraoka J, Hirabayashi H, Kawamata T, Kawamoto K, Kitahara T, Kojima J, Kuroiwa T, Mori T, Moro N, Nagata I, Ogawa A, Ohno K, Seiki Y, Shiokawa Y, Teramoto A, Tominaga T, Yoshimine T: A randomized controlled trial of hydrocortisone against hyponatremia in patients with aneurysmal subarachnoid hemorrhage. Stroke 2007;38:2373-2375.

92 Ohkuma H, Tsurutani H, Suzuki S: Incidence and significance of early aneurysmal rebleeding before neurosurgical or neurological management. Stroke 2001;32:11761180.

93 Hijdra A, Vermeulen M, van Gijn J, van Crevel H: Rerupture of intracranial aneurysms: a clinicoanatomic study. J Neurosurg 1987;67:29-33.

94 de Gans K, Nieuwkamp DJ, Rinkel GJ, Algra A: Timing of aneurysm surgery in subarachnoid hemorrhage: a systematic review of the literature. Neurosurgery 2002;50:336-340, discussion pp 340-332. $\checkmark 95$ Laidlaw JD, Siu KH: Poor-grade aneurysmal subarachnoid hemorrhage: outcome after treatment with urgent surgery. Neurosurgery 2003;53:1275-1280, discussion pp $1280-1272$.

96 Raabe A, Nakaji P, Beck J, Kim LJ, Hsu FP, Kamerman JD, Seifert V, Spetzler RF: Prospective evaluation of surgical microscopeintegrated intraoperative near-infrared indocyanine green videoangiography during aneurysm surgery. J Neurosurg 2005;103: 982-989.

97 Molyneux A, Kerr R, Stratton I, Sandercock P, Clarke M, Shrimpton J, Holman R: International Subarachnoid Aneurysm Trial (ISAT) of neurosurgical clipping versus endovascular coiling in 2,143 patients with ruptured intracranial aneurysms: a randomised trial. Lancet 2002;360:1267-1274.

$\$ 98$ Molyneux AJ, Kerr RS, Birks J, Ramzi N, Yarnold J, Sneade M, Rischmiller J: Risk of recurrent subarachnoid haemorrhage, death, or dependence and standardised mortality ratios after clipping or coiling of an intracranial aneurysm in the International Subarachnoid Aneurysm Trial (ISAT): long-term follow-up. Lancet Neurol 2009;8:427-433.

99 Campi A, Ramzi N, Molyneux AJ, Summers PE, Kerr RS, Sneade M, Yarnold JA, Rischmiller J, Byrne JV: Retreatment of ruptured cerebral aneurysms in patients randomized by coiling or clipping in the International Subarachnoid Aneurysm Trial (ISAT). Stroke 2007;38:1538-1544.

100 Mitchell P, Kerr R, Mendelow AD, Molyneux A: Could late rebleeding overturn the superiority of cranial aneurysm coil embolization over clip ligation seen in the International Subarachnoid Aneurysm Trial? J Neurosurg 2008; 108:437-442.

101 Choudhari KA, Ramachandran MS, McCarron MO, Kaliaperumal C: Aneurysms unsuitable for endovascular intervention: surgical outcome and management challenges over a 5-year period following International Subarachnoid Haemorrhage Trial (ISAT). Clin Neurol Neurosurg 2007;109: 868-875.

102 O'Kelly CJ, Kulkarni AV, Austin PC, Wallace MC, Urbach D: The impact of therapeutic modality on outcomes following repair of ruptured intracranial aneurysms: an administrative data analysis. Clinical article. J Neurosurg 2010;113:795-801.

103 Johnston SC, Dowd CF, Higashida RT, Lawton MT, Duckwiler GR, Gress DR: Predictors of rehemorrhage after treatment of ruptured intracranial aneurysms: the Cerebral Aneurysm Rerupture after Treatment (CARAT) study. Stroke 2008;39:120-125.

104 Elijovich L, Higashida RT, Lawton MT, Duckwiler G, Giannotta S, Johnston SC: Predictors and outcomes of intraprocedural rupture in patients treated for ruptured intracranial aneurysms: the CARAT study. Stroke 2008;39:1501-1506. 
105 Guo XB, Fan YM, Zhang JN: HydroSoft coil versus HydroCoil for endovascular aneurysm occlusion study: a single center experience. Eur J Radiol 2011;79:e42-46.

106 Geyik S, Ertugrul O, Yavuz K, Geyik P, Saatci I, Cekirge HS: Comparison of bioactive coils and bare platinum coils for treatment of intracranial aneurysms: a matched-pair analysis. J Neurosurg 2010;112:709-713.

-107 Ryttlefors M, Enblad P, Kerr RS, Molyneux AJ: International subarachnoid aneurysm trial of neurosurgical clipping versus endovascular coiling: subgroup analysis of 278 elderly patients. Stroke 2008;39:2720-2726.

108 Roos YB, Rinkel GJ, Vermeulen M, Algra A, van Gijn J: Antifibrinolytic therapy for aneurysmal subarachnoid haemorrhage. Cochrane Database Syst Rev 2003:CD001245.

109 Hillman J, Fridriksson S, Nilsson O, Yu Z, Saveland H, Jakobsson KE: Immediate administration of tranexamic acid and reduced incidence of early rebleeding after aneurysmal subarachnoid hemorrhage: a prospective randomized study. J Neurosurg 2002;97: 771-778.

110 Rinkel GJ, Klijn CJ: Prevention and treatment of medical and neurological complications in patients with aneurysmal subarachnoid haemorrhage. Pract Neurol 2009;9:195-209.

-111 Pickard JD, Kirkpatrick PJ, Melsen T, Andreasen RB, Gelling L, Fryer T, Matthews J, Minhas P, Hutchinson PJ, Menon D, Downey SP, Kendall I, Clark J, Carpenter TA, Williams E, Persson L: Potential role of NovoSeven in the prevention of rebleeding following aneurysmal subarachnoid haemorrhage. Blood Coagul Fibrinolysis 2000; 11(suppl 1):S117-S120.

-112 Heros RC: Acute hydrocephalus after subarachnoid hemorrhage. Stroke 1989;20: 715-717.

-113 Hasan D, Tanghe HL: Distribution of cisternal blood in patients with acute hydrocephalus after subarachnoid hemorrhage. Ann Neurol 1992;31:374-378.

114 Rinkel GJ, Wijdicks EF, Vermeulen M, Tans JT, Hasan D, van Gijn J: Acute hydrocephalus in nonaneurysmal perimesencephalic hemorrhage: evidence of CSF block at the tentorial hiatus. Neurology 1992;42:18051807.

-115 Auer LM, Mokry M: Disturbed cerebrospinal fluid circulation after subarachnoid hemorrhage and acute aneurysm surgery. Neurosurgery 1990;26:804-808, discussion pp 808-809.

116 Bailes JE, Spetzler RF, Hadley MN, Baldwin HZ: Management, morbidity and mortality of poor-grade aneurysm patients. J Neurosurg 1990;73:559-566.

-117 Bota DP, Lefranc F, Vilallobos HR, Brimioulle S, Vincent JL: Ventriculostomy-related infections in critically ill patients: a 6-year experience. J Neurosurg 2005; 103:468-472.
118 Huttner HB, Schwab S, Bardutzky J: Lumbar drainage for communicating hydrocephalus after ICH with ventricular hemorrhage. Neurocrit Care 2006;5:193-196.

119 Huttner HB, Nagel S, Tognoni E, Kohrmann M, Juttler E, Orakcioglu B, Schellinger PD, Schwab S, Bardutzky J: Intracerebral hemorrhage with severe ventricular involvement: lumbar drainage for communicating hydrocephalus. Stroke 2007;38:183-187.

120 Dorhout Mees SM, Rinkel GJ, Feigin VL, Algra A, van den Bergh WM, Vermeulen $\mathrm{M}$, van Gijn J: Calcium antagonists for aneurysmal subarachnoid haemorrhage. Cochrane Database Syst Rev 2007:CD000277.

-121 Pickard JD, Murray GD, Illingworth R, Shaw MD, Teasdale GM, Foy PM, Humphrey PR, Lang DA, Nelson R, Richards P, et al: Effect of oral nimodipine on cerebral infarction and outcome after subarachnoid haemorrhage: British aneurysm nimodipine trial. BMJ 1989;298:636-642.

122 Barth M, Capelle HH, Weidauer S, Weiss C, Munch E, Thome C, Luecke T, Schmiedek P, Kasuya H, Vajkoczy P: Effect of nicardipine prolonged-release implants on cerebral vasospasm and clinical outcome after severe aneurysmal subarachnoid hemorrhage: a prospective, randomized, doubleblind phase IIa study. Stroke 2007;38:330336.

123 Kasuya H, Onda H, Sasahara A, Takeshita M, Hori T: Application of nicardipine prolonged-release implants: analysis of $97 \mathrm{con}$ secutive patients with acute subarachnoid hemorrhage. Neurosurgery 2005;56:895902, discussion pp 895-902.

124 Vergouwen MD, Meijers JC, Geskus RB, Coert BA, Horn J, Stroes ES, van der Poll T, Vermeulen M, Roos YB: Biologic effects of simvastatin in patients with aneurysmal subarachnoid hemorrhage: a double-blind, placebo-controlled randomized trial. J Cereb Blood Flow Metab 2009;29:14441453.

125 Vergouwen MD, de Haan RJ, Vermeulen M, Roos YB: Effect of statin treatment on vasospasm, delayed cerebral ischemia, and functional outcome in patients with aneurysmal subarachnoid hemorrhage: a systematic review and meta-analysis update. Stroke 2010;41:e47-e52.

-126 Dorhout Mees SM, van den Bergh WM, Algra A, Rinkel GJ: Achieved serum magnesium concentrations and occurrence of delayed cerebral ischaemia and poor outcome in aneurysmal subarachnoid haemorrhage. J Neurol Neurosurg Psychiatry 2007;78: 729-731.

127 Mees SM, Algra A, Vandertop WP, van Kooten F, Kuijsten HA, Boiten J, van Oostenbrugge RJ, Salman RA, Lavados PM, Rinkel GJ, van den Bergh WM: Magnesium for aneurysmal subarachnoid haemorrhage (MASH-2): a randomised placebo-controlled trial. Lancet 2012;380:44-49.
128 Kosnik EJ, Hunt WE: Postoperative hypertension in the management of patients with intracranial arterial aneurysms. J Neurosurg 1976;45:148-154.

129 Amin-Hanjani S, Schwartz RB, Sathi S, Stieg PE: Hypertensive encephalopathy as a complication of hyperdynamic therapy for vasospasm: report of two cases. Neurosurgery 1999;44:1113-1116.

130 Wartenberg KE, Parra A: CT and CT-perfusion findings of reversible leukoencephalopathy during triple- $\mathrm{H}$ therapy for symptomatic subarachnoid hemorrhagerelated vasospasm. J Neuroimaging 2006; 16:170-175.

131 Rinkel GJ, Wijdicks EF, Hasan D, Kienstra GE, Franke CL, Hageman LM, Vermeulen $\mathrm{M}$, van Gijn J: Outcome in patients with subarachnoid haemorrhage and negative angiography according to pattern of haemorrhage on computed tomography. Lancet 1991;338:964-968.

132 van Gijn J, Kerr RS, Rinkel GJ: Subarachnoid haemorrhage. Lancet 2007;369:306318.

133 Flaherty ML, Haverbusch M, Kissela B, Kleindorfer D, Schneider A, Sekar P, Moomaw CJ, Sauerbeck L, Broderick JP, Woo D: Perimesencephalic subarachnoid hemorrhage: incidence, risk factors, and outcome. J Stroke Cerebrovasc Dis 2005; 14:267-271.

134 Kaufmann TJ, Huston J3rd, Mandrekar JN, Schleck CD, Thielen KR, Kallmes DF Complications of diagnostic cerebral angiography: evaluation of 19,826 consecutive patients. Radiology 2007;243:812-819.

135 Dawkins AA, Evans AL, Wattam J, Romanowski CA, Connolly DJ, Hodgson TJ, Coley SC: Complications of cerebral angiography: a prospective analysis of 2,924 consecutive procedures. Neuroradiology 2007;49:753-759.

136 Ruigrok YM, Rinkel GJ, Buskens E, Velthuis BK, van Gijn J: Perimesencephalic hemorrhage and CT angiography: a decision analysis. Stroke 2000;31:2976-2983.

137 Velthuis BK, Rinkel GJ, Ramos LM, Witkamp TD, van Leeuwen MS: Perimesencephalic hemorrhage. Exclusion of vertebrobasilar aneurysms with CT angiography. Stroke 1999;30:1103-1109.

138 Huttner HB, Hartmann M, Kohrmann M, Neher M, Stippich C, Hahnel S, Kress B: Repeated digital substraction angiography after perimesencephalic subarachnoid hemorrhage? J Neuroradiol 2006;33:87-89.

139 Schwartz TH, Solomon RA: Perimesencephalic nonaneurysmal subarachnoid hemorrhage: review of the literature. Neurosurgery 1996;39:433-440, discussion p 440.
Guidelines for Management of Intracranial Aneurysms and SAH
Cerebrovasc Dis 2013;35:93-112 DOI: $10.1159 / 000346087$ 
140 Hui FK, Tumialan LM, Tanaka T, Cawley CM, Zhang YJ: Clinical differences between angiographically negative, diffuse subarachnoid hemorrhage and perimesencephalic subarachnoid hemorrhage. Neurocrit Care 2009;11:64-70.

141 Kang DH, Park J, Lee SH, Park SH, Kim YS, Hamm IS: Does non-perimesencephalic type non-aneurysmal subarachnoid hemorrhage have a benign prognosis? J Clin Neurosci 2009; 16:904-908.

142 Hsu W, Pradilla G, Garonzik IM, Conway JE: Pretruncal nonaneurysmal subarachnoid hemorrhage causing basilar artery vasospasm. Neurocrit Care 2010;13:256-260.

143 Mayor S, Erro ME, Zazpe I, Gallego J: Pontine stroke due to vasospasm secondary to perimesencephalic subarachnoid hemorrhage (in Spanish). Neurologia 2008;23:256258.

144 Rinkel GJ, Wijdicks EF, Vermeulen M, Hasan D, Brouwers PJ, van Gijn J: The clinical course of perimesencephalic nonaneurysmal subarachnoid hemorrhage. Ann Neurol 1991;29:463-468.

145 Greebe P, Rinkel GJ: Life expectancy after perimesencephalic subarachnoid hemorrhage. Stroke 2007;38:1222-1224.
146 van der Schaaf IC, Velthuis BK, Gouw A, Rinkel GJ: Venous drainage in perimesencephalic hemorrhage. Stroke 2004;35:16141618.

147 Urbach H, Zentner J, Solymosi L: The need for repeat angiography in subarachnoid haemorrhage. Neuroradiology 1998;40:610.

148 Topcuoglu MA, Ogilvy CS, Carter BS, Buonanno FS, Koroshetz WJ, Singhal AB: Subarachnoid hemorrhage without evident cause on initial angiography studies: diagnostic yield of subsequent angiography and other neuroimaging tests. J Neurosurg 2003;98:1235-1240.

149 Kaim A, Proske M, Kirsch E, von Weymarn A, Radu EW, Steinbrich W: Value of repeatangiography in cases of unexplained subarachnoid hemorrhage (SAH). Acta Neurol Scand 1996;93:366-373.

150 Jung JY, Kim YB, Lee JW, Huh SK, Lee KC: Spontaneous subarachnoid haemorrhage with negative initial angiography: a review of 143 cases. J Clin Neurosci 2006;13:10111017.

151 Inamasu J, Nakamura Y, Saito R, Horiguchi T, Kuroshima Y, Mayanagi K, Orii M, Ichikizaki K: 'Occult' ruptured cerebral aneurysms revealed by repeat angiography: result from a large retrospective study. Clin Neurol Neurosurg 2003;106:33-37.
152 International Study of Unruptured Intracranial Aneurysms Investigators: Unruptured intracranial aneurysms - risk of rupture and risks of surgical intervention. $\mathrm{N}$ Engl J Med 1998;339:1725-1733.

153 Juvela S, Porras M, Heiskanen O: Natural history of unruptured intracranial aneurysms: a long-term follow-up study. J Neurosurg 1993;79:174-182.

154 Juvela S: Natural history of unruptured intracranial aneurysms: risks for aneurysm formation, growth, and rupture. Acta Neurochir Suppl 2002;82:27-30.

155 Bavinzski G, Talazoglu V, Killer M, Richling B, Gruber A, Gross CE, Plenk H Jr: Gross and microscopic histopathological findings in aneurysms of the human brain treated with Guglielmi detachable coils. J Neurosurg 1999;91:284-293.

156 Raaymakers TW, Rinkel GJ, Limburg M, Algra A: Mortality and morbidity of surgery for unruptured intracranial aneurysms: a meta-analysis. Stroke 1998;29: 1531-1538.

157 Teasdale G, Jennett B: Assessment of coma and impaired consciousness. A practical scale. Lancet 1974;2:81-84. 